\title{
Phase behavior of alkyne-functionalized styrenic block copolymer/cobalt carbonyl adducts and in situ formation of magnetic nanoparticles by thermolysis
}

Bingyin Jiang, ${ }^{\dagger}$ Dmytro Nykypanchuk, " Maya K. Endoh, ${ }^{+}$Xianyin Chen, ${ }^{\dagger}$ Bin Qian,,$^{\dagger}$ Kim

Kisslinger, " Tadanori Koga, ${ }^{+}$John B. Parise, ${ }^{\dagger, \S}$ Robert B. Grubbs ${ }^{* \dagger}$

${ }^{\dagger}$ Department of Chemistry, Stony Brook University, Stony Brook, NY 11794-3400, USA.

Department of Materials Science and Engineering and Chemical and Molecular Engineering Program, Stony Brook University, Stony Brook, New York 11794-2275, USA.

${ }^{\S}$ Department of Geosciences, Stony Brook University, Stony Brook, NY 11794-2100,USA.

"Center for Functional Nanomaterials, Brookhaven National Laboratory, Upton, NY 11973, United States

Email: robert.grubbs@stonybrook.edu 


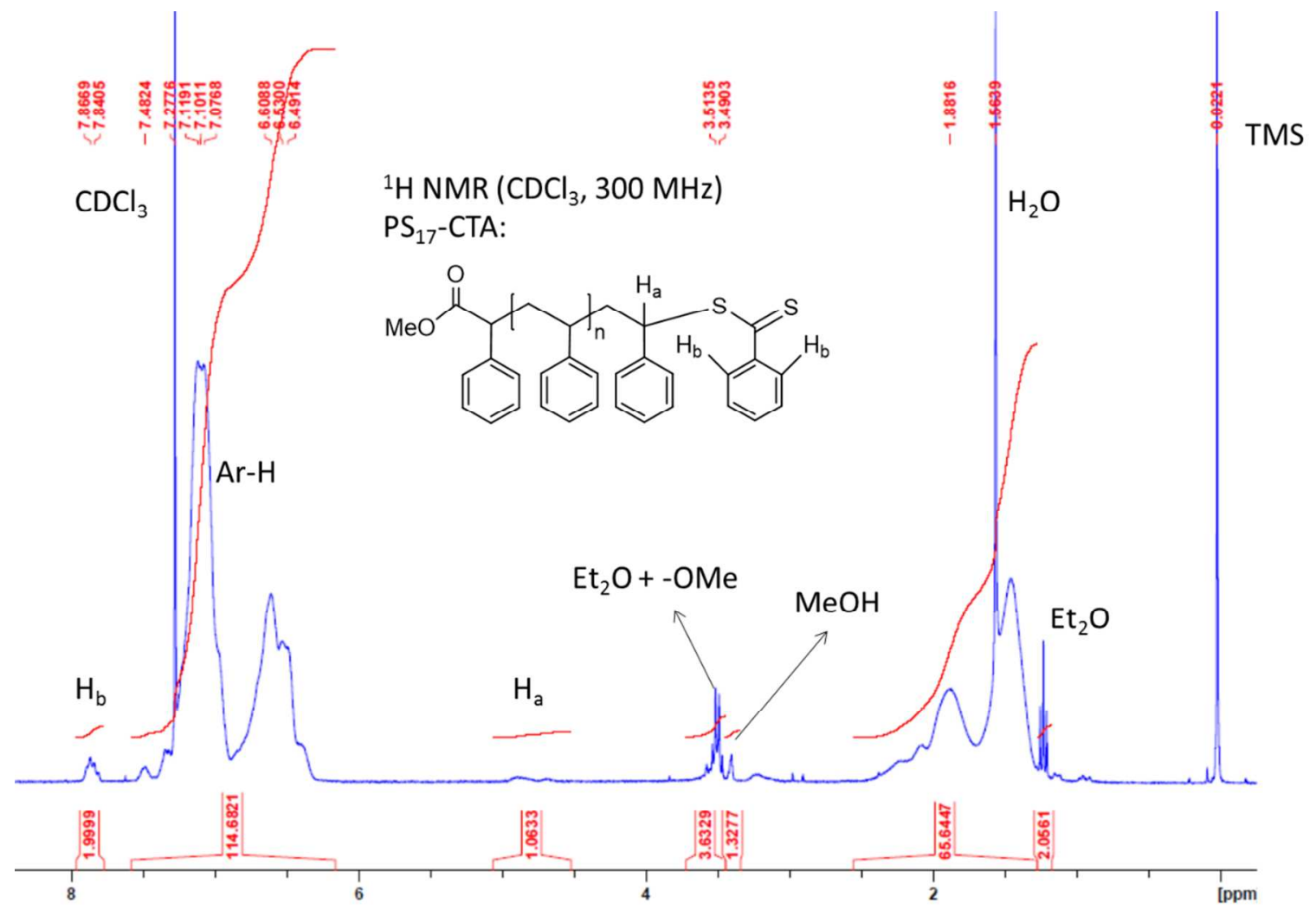

Figure S1. ${ }^{1} \mathrm{H}$ NMR spectrum of $\mathrm{PS}_{17}-\mathrm{CTA}$. The end group peaks $\mathrm{H}_{\mathrm{a}}$ and $\mathrm{H}_{\mathrm{b}}$ are assigned according to published results. ${ }^{1,2}$ 


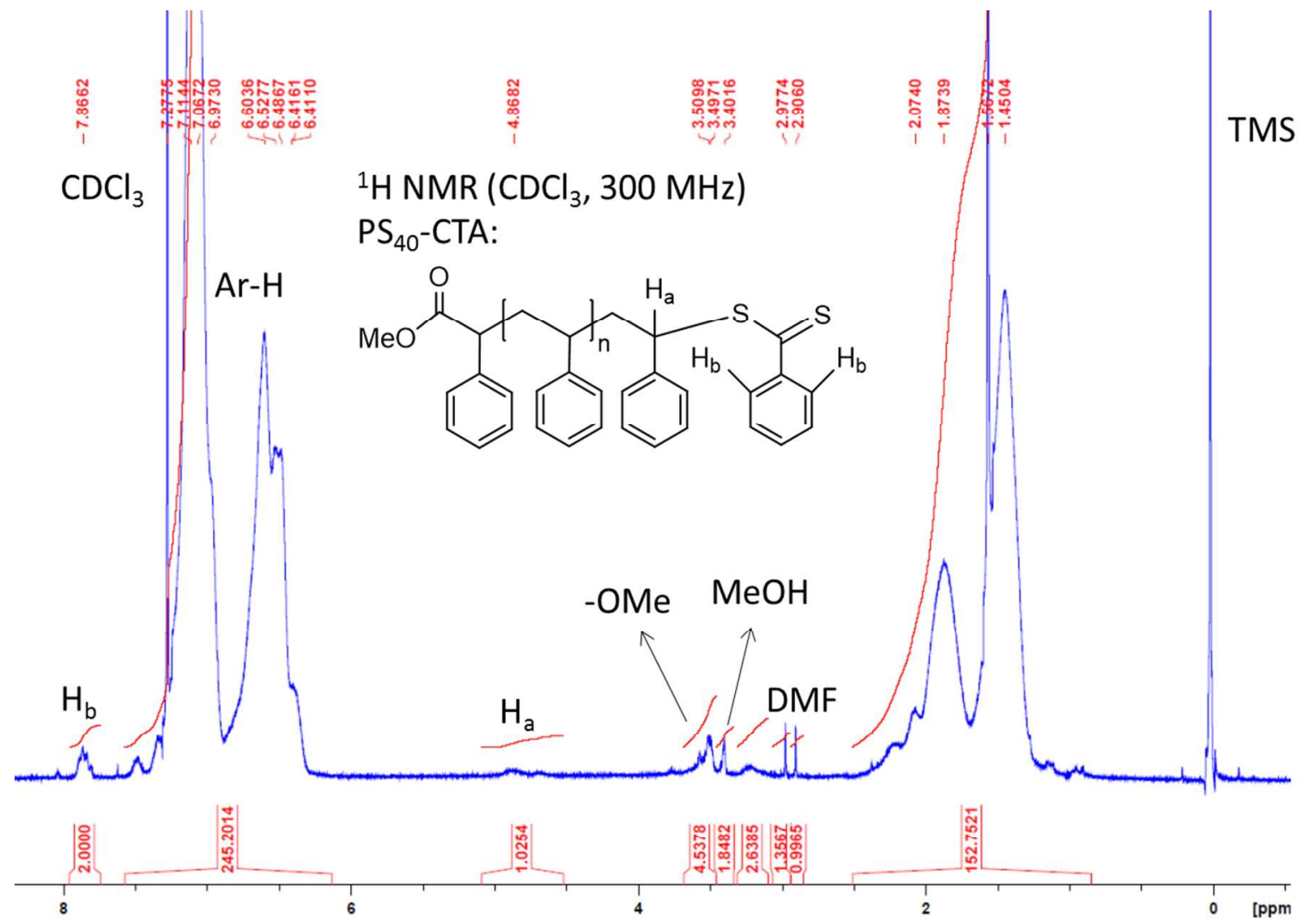

Figure S2. ${ }^{1} \mathrm{H}$ NMR spectrum of $\mathrm{PS}_{40}$-CTA. The end group peaks $\mathrm{H}_{\mathrm{a}}$ and $\mathrm{H}_{\mathrm{b}}$ are assigned according to published results. ${ }^{1,2}$ 


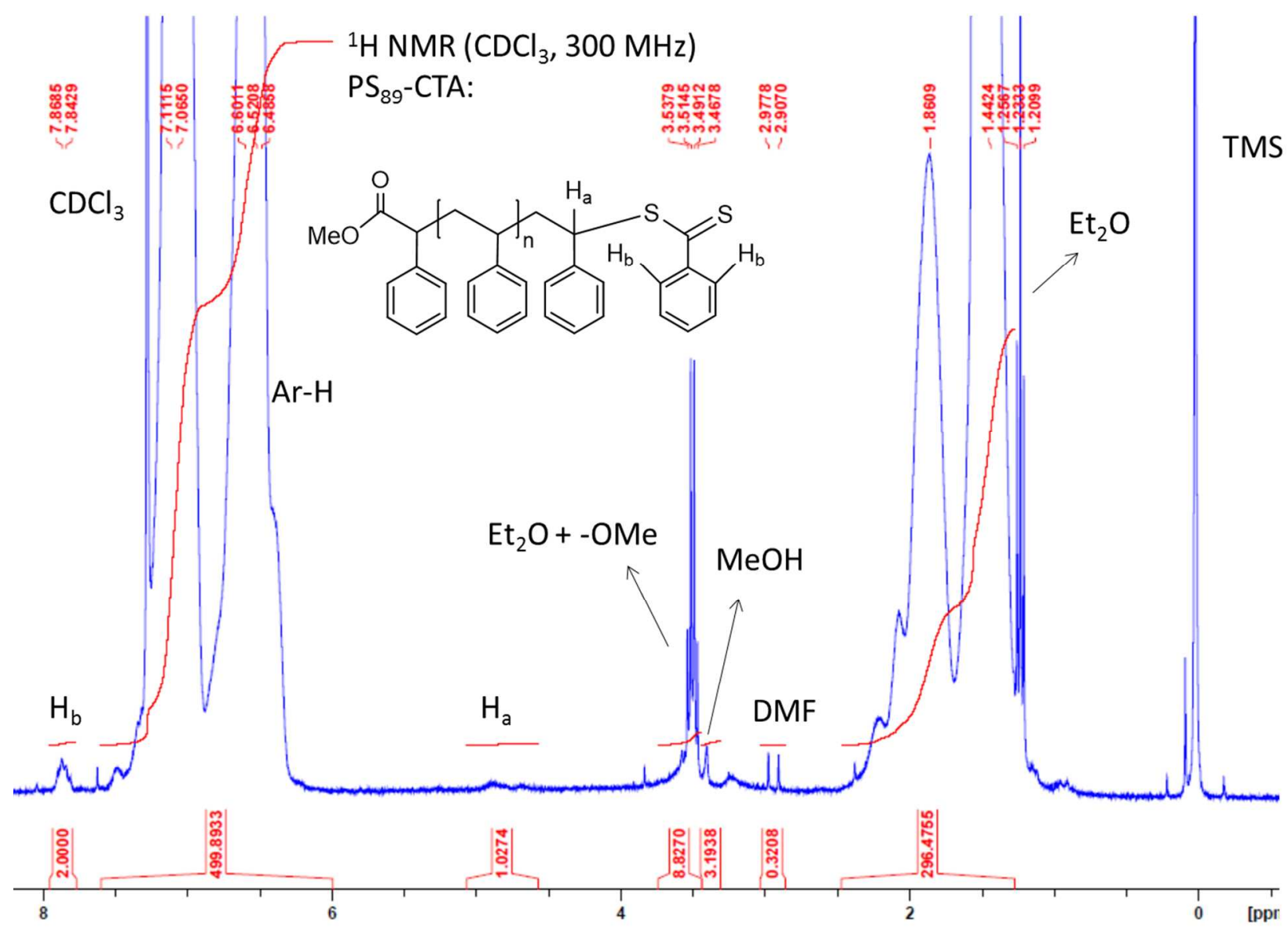

Figure S3. NMR spectrum of $\mathrm{PS}_{89}$-CTA. The end group peaks $\mathrm{H}_{\mathrm{a}}$ and $\mathrm{H}_{\mathrm{b}}$ are assigned according to published results. ${ }^{1,2}$ 


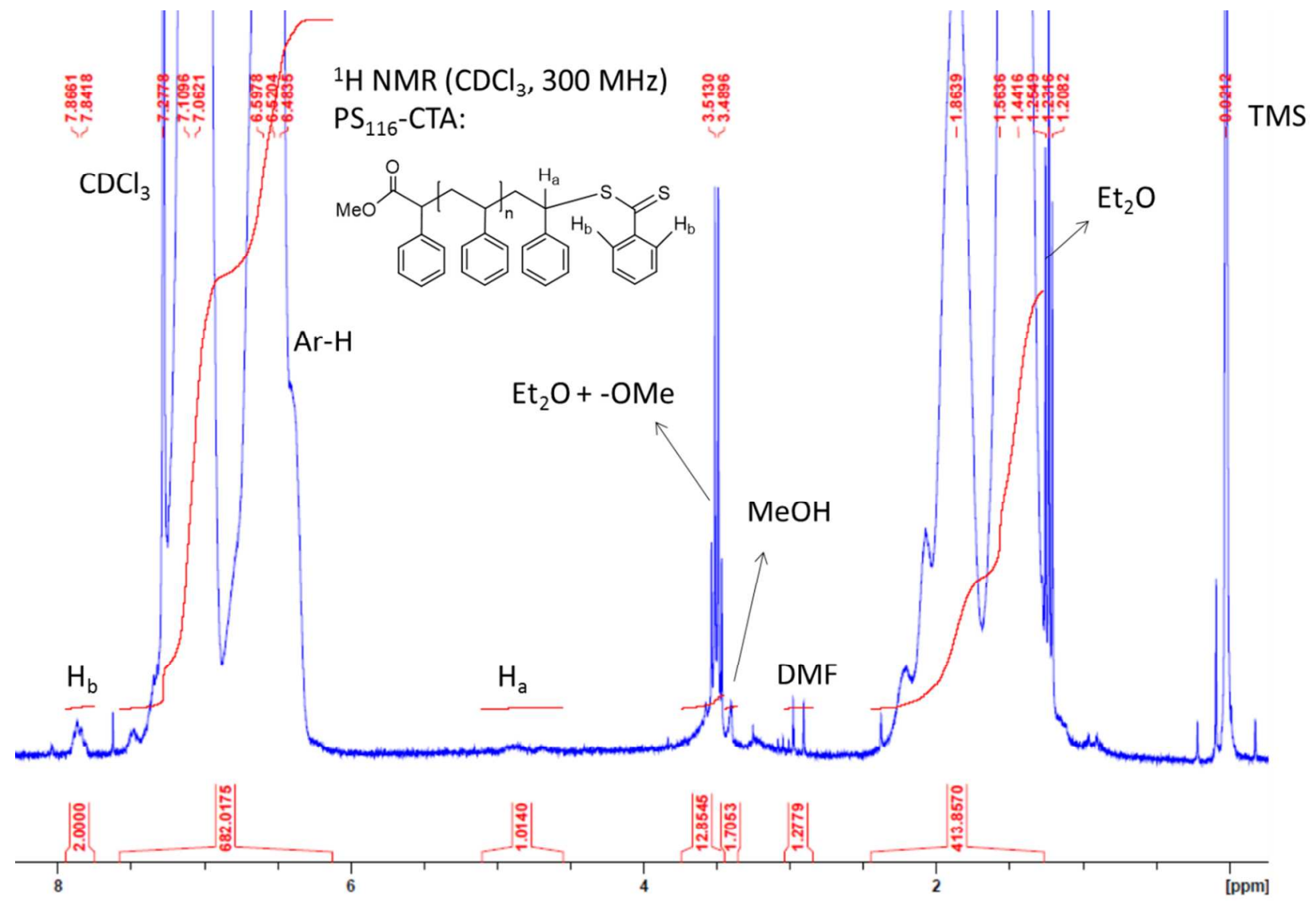

Figure S4. NMR spectrum of $\mathrm{PS}_{116}$-CTA. The end group peaks $\mathrm{H}_{\mathrm{a}}$ and $\mathrm{H}_{\mathrm{b}}$ are assigned according to published results. ${ }^{1,2}$ 


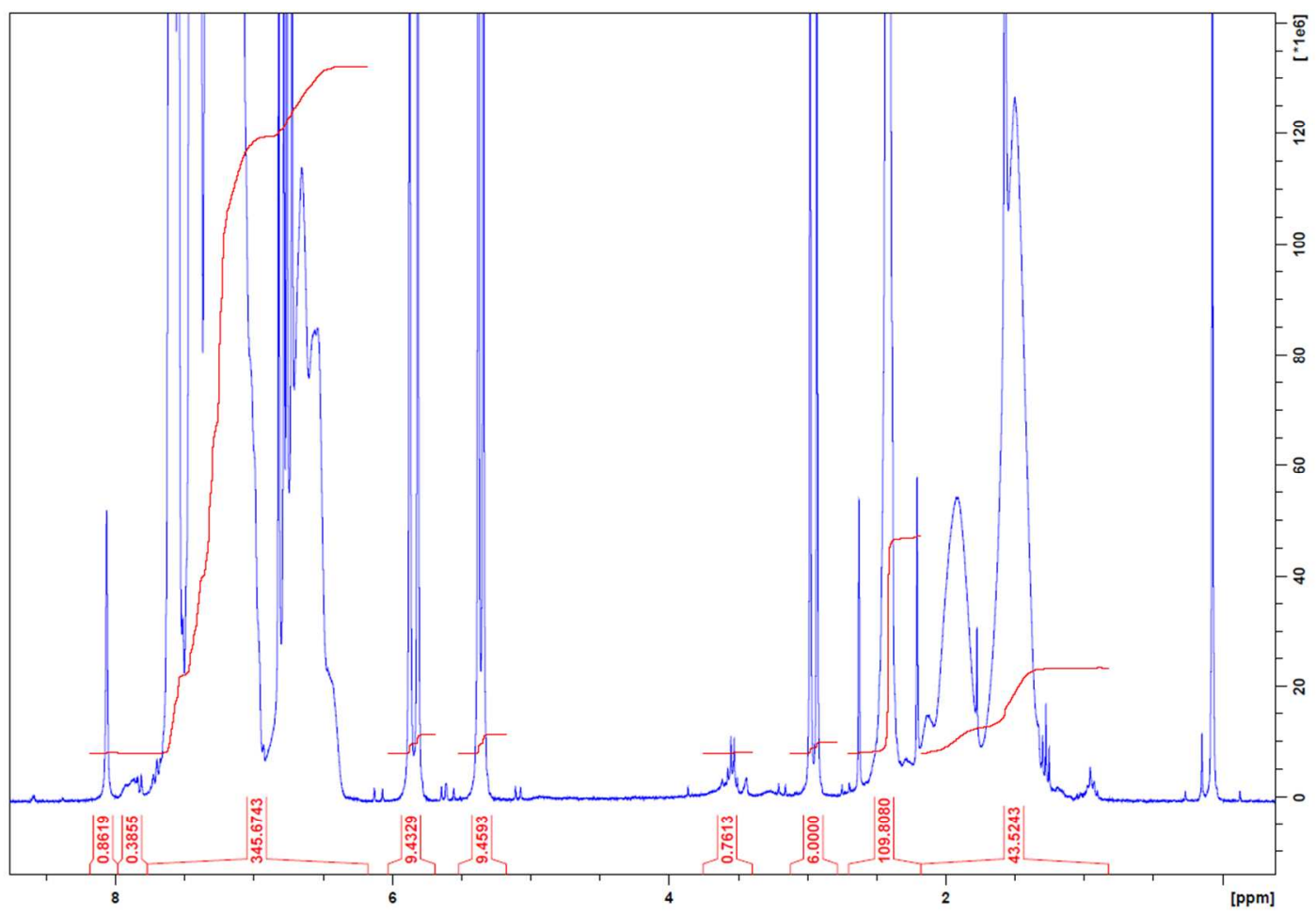

Figure S5. Representative ${ }^{1} \mathrm{H}$ NMR spectrum of initial reaction mixture that resulted in $\mathrm{PS}_{89^{-}}$ $\mathrm{PPES}_{41}$. 


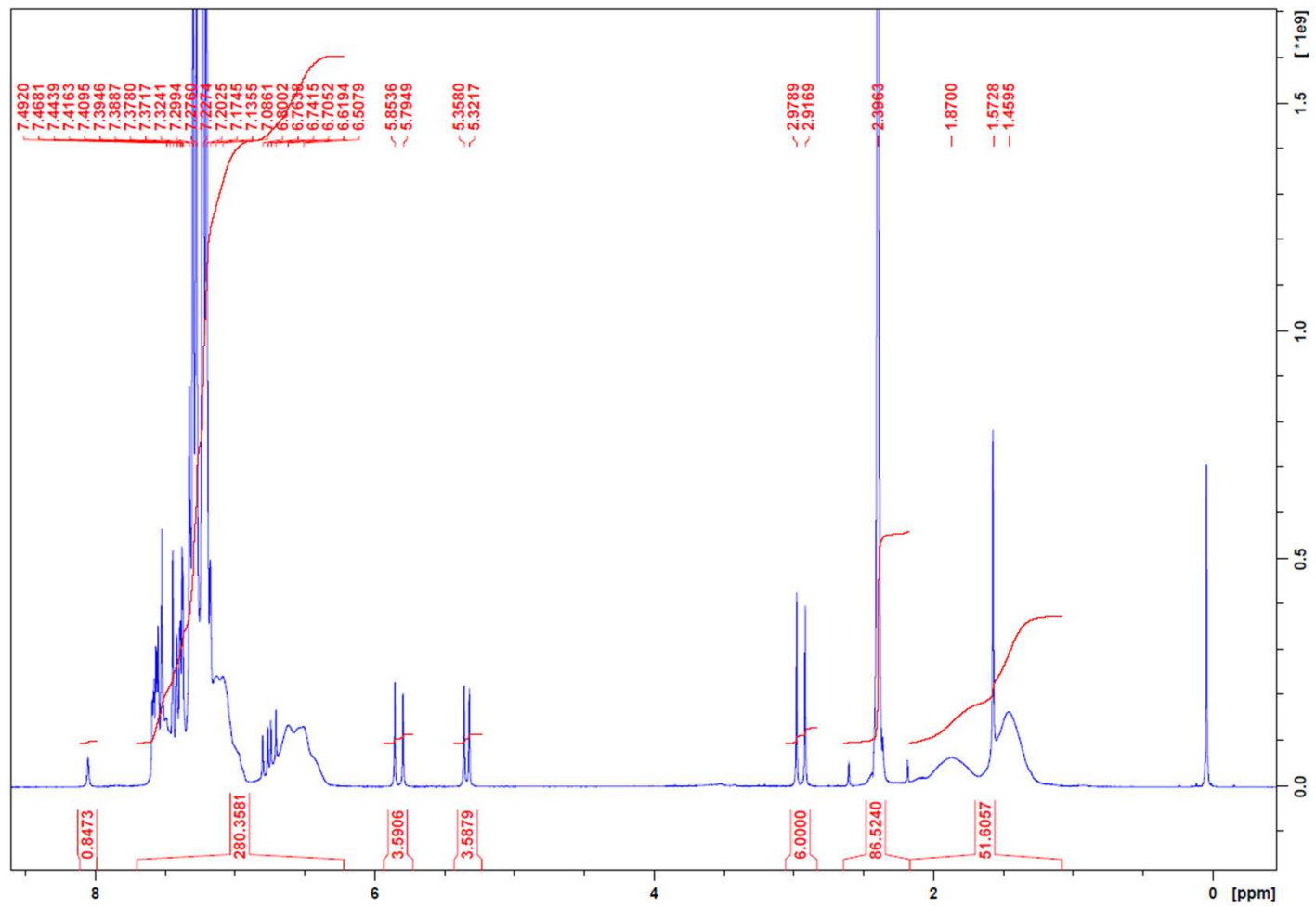

Figure S6. Representative ${ }^{1} \mathrm{H}$ NMR spectrum of final reaction mixture for sample $\mathrm{PS}_{89}-\mathrm{PPES}_{41}$. 


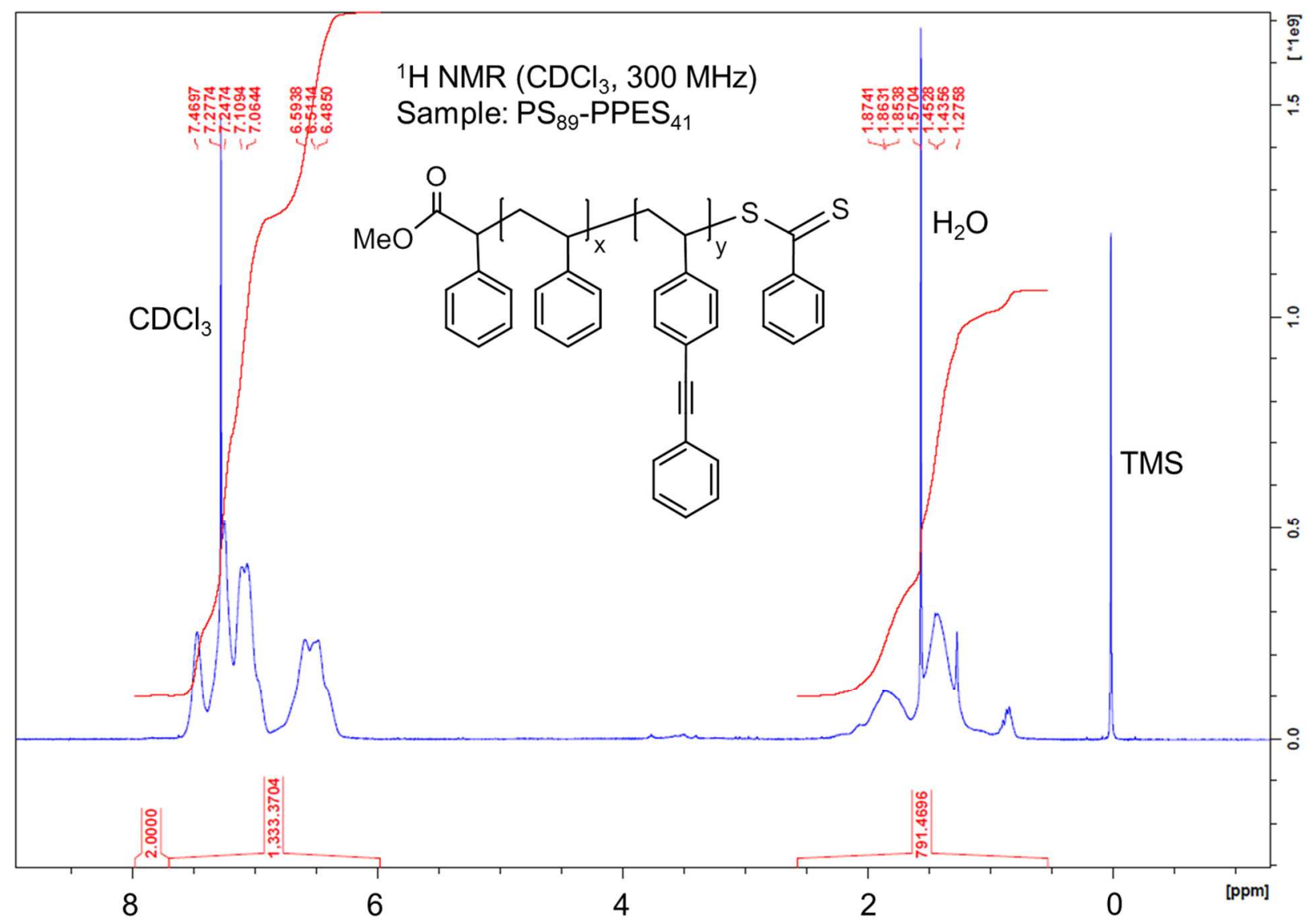

Figure S7. Representative ${ }^{1} \mathrm{H}$ NMR spectrum of purified $\mathrm{PS}_{\mathrm{x}}-b-\mathrm{PPES}_{\mathrm{y}}$ diblock copolymer (sample $\mathrm{PS}_{89}-\mathrm{PPES}_{41}$ ). 


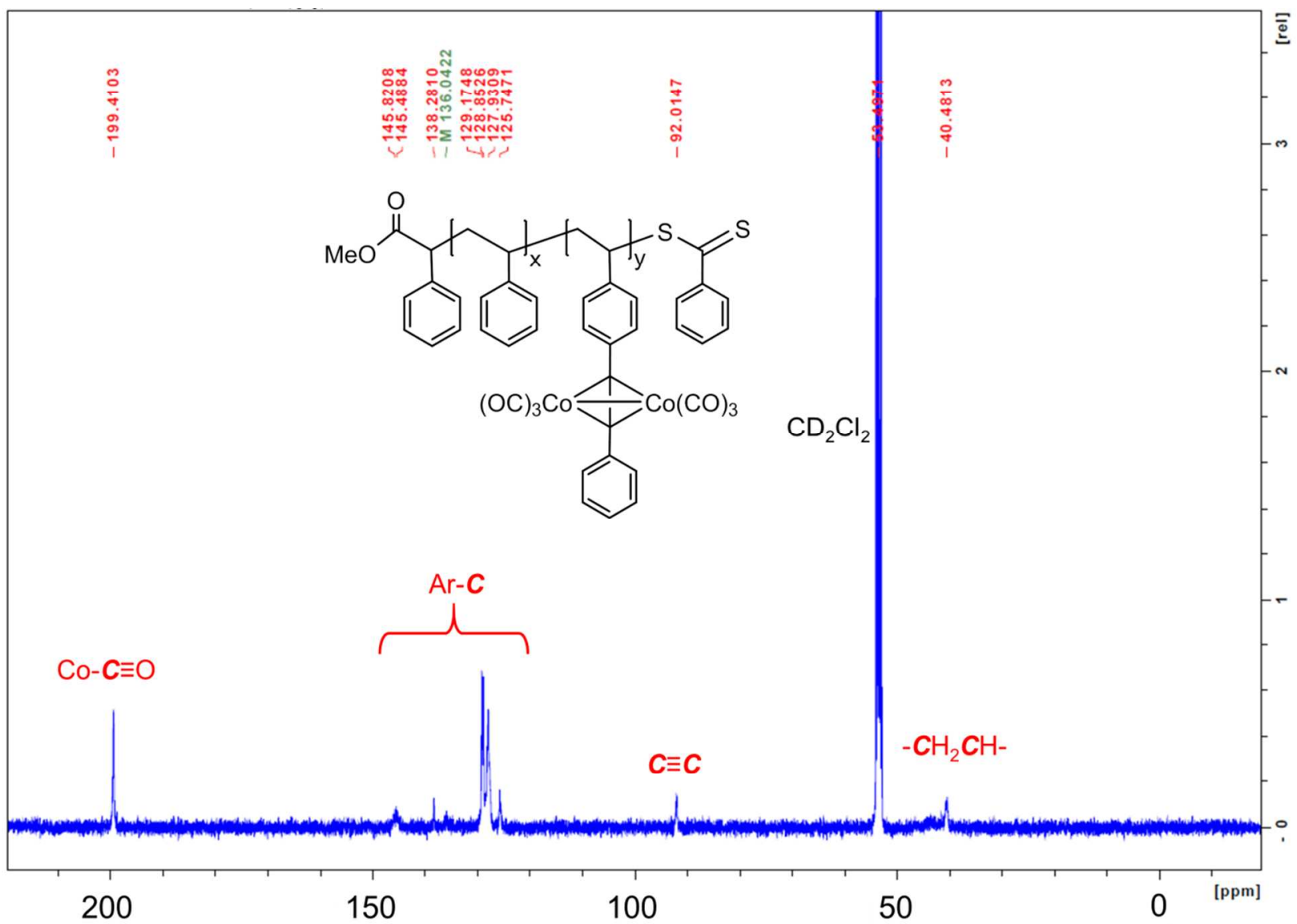

Figure S8. Representative ${ }^{13} \mathrm{C}$ NMR spectrum of purified $\mathrm{PS}_{\mathrm{x}}-\mathrm{PPES}_{\mathrm{y}}\left[\mathrm{Co}_{2}(\mathrm{CO})_{6}\right]_{\mathrm{n}}$ diblock copolymer cobalt adduct (sample $\mathrm{PS}_{40}-\mathrm{PPES}_{39}\left[\mathrm{Co}_{2}(\mathrm{CO})_{6}\right]_{33}$ ). The peaks are assigned according to previously reported spectra of similar polymers. ${ }^{3-6}$ 


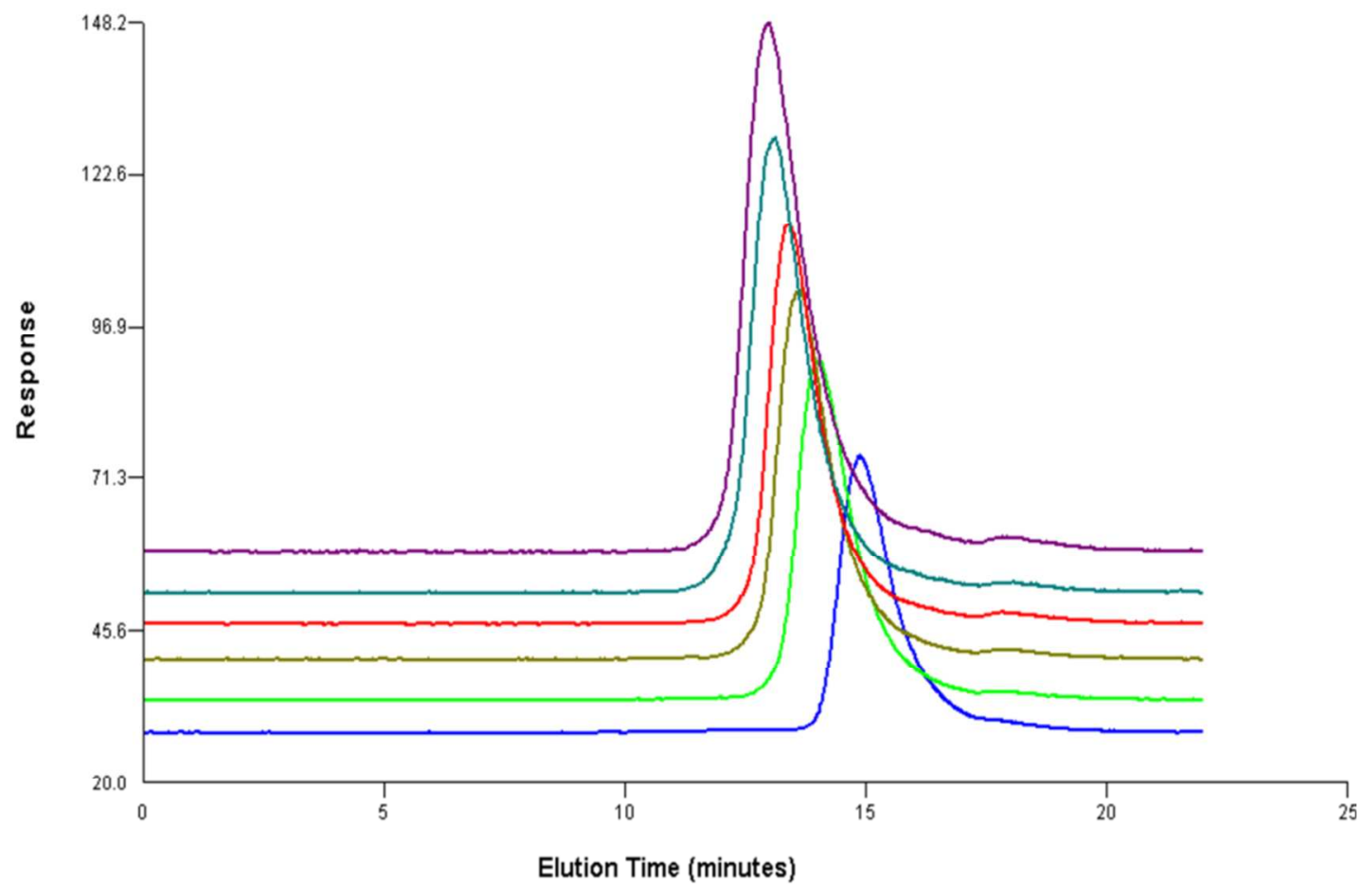

Figure S9. GPC traces of the $\mathrm{PS}_{17}$-series diblock copolymers. Eluent: THF. Flow rate: $1.0 \mathrm{~mL} / \mathrm{min}$. From bottom to top: $\mathrm{PS}_{17}-\mathrm{CTA}$ (blue), $\mathrm{PS}_{17}-\mathrm{PPES}_{8}$ (green), $\mathrm{PS}_{17}-\mathrm{PPES}_{19}$ (dark khaki), $\mathrm{PS}_{17}-\mathrm{PPES}_{28}$ (red), $\mathrm{PS}_{17}-\mathrm{PPES}_{30}$ (light sea green), and $\mathrm{PS}_{17}-\mathrm{PPES}_{46}$ (purple).

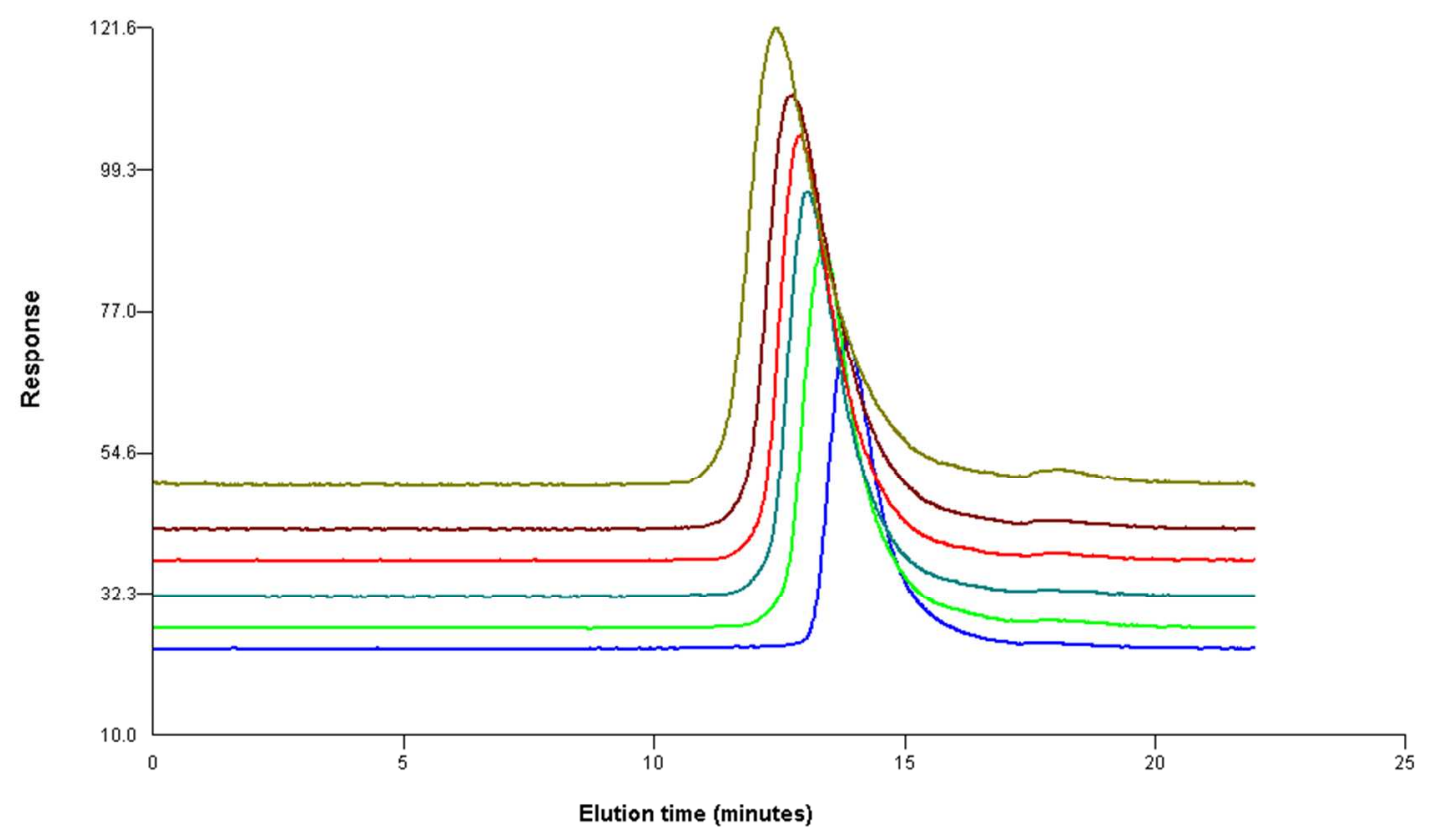

Figure S10. GPC traces of the $\mathrm{PS}_{40}$-series diblock copolymers. Eluent: THF. Flow rate: $1.0 \mathrm{~mL} / \mathrm{min}$. From bottom to top: $\mathrm{PS}_{40}-\mathrm{CTA}$ (blue), $\mathrm{PS}_{40}-\mathrm{PPES}_{11}$ (light green), $\mathrm{PS}_{40}-\mathrm{PPES}_{20}$ (light sea green), $\mathrm{PS}_{40}-\mathrm{PPES}_{32}$ (red), $\mathrm{PS}_{40}-\mathrm{PPES}_{39}$ (purple), $\mathrm{PS}_{40}-\mathrm{PPES}_{74}$ (dark khaki). 


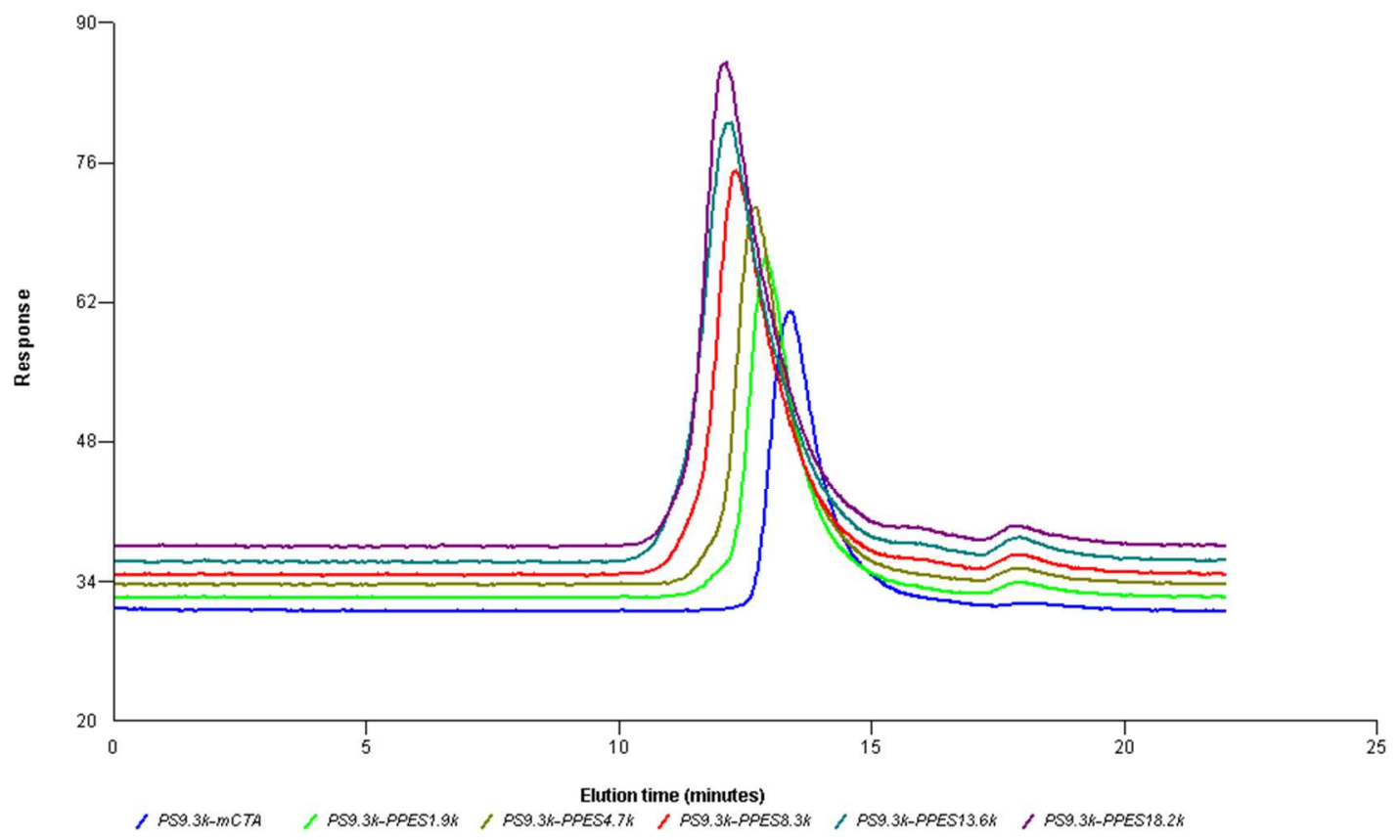

Figure S11. GPC traces of the $\mathrm{PS}_{89}$-series diblock copolymers. Eluent: THF. Flow rate: $1.0 \mathrm{~mL} / \mathrm{min}$. From bottom to top: $\mathrm{PS}_{89}-\mathrm{CTA}$ (blue), $\mathrm{PS}_{89}-\mathrm{PPES}_{9}$ (light green), $\mathrm{PS}_{89}-\mathrm{PPES}_{23}$ (dark khaki), $\mathrm{PS}_{89}-\mathrm{PPES}_{41}$ (red), $\mathrm{PS}_{89}-\mathrm{PPES}_{67}$ (light sea green), $\mathrm{PS}_{89}-\mathrm{PPES}_{89}$ (purple).

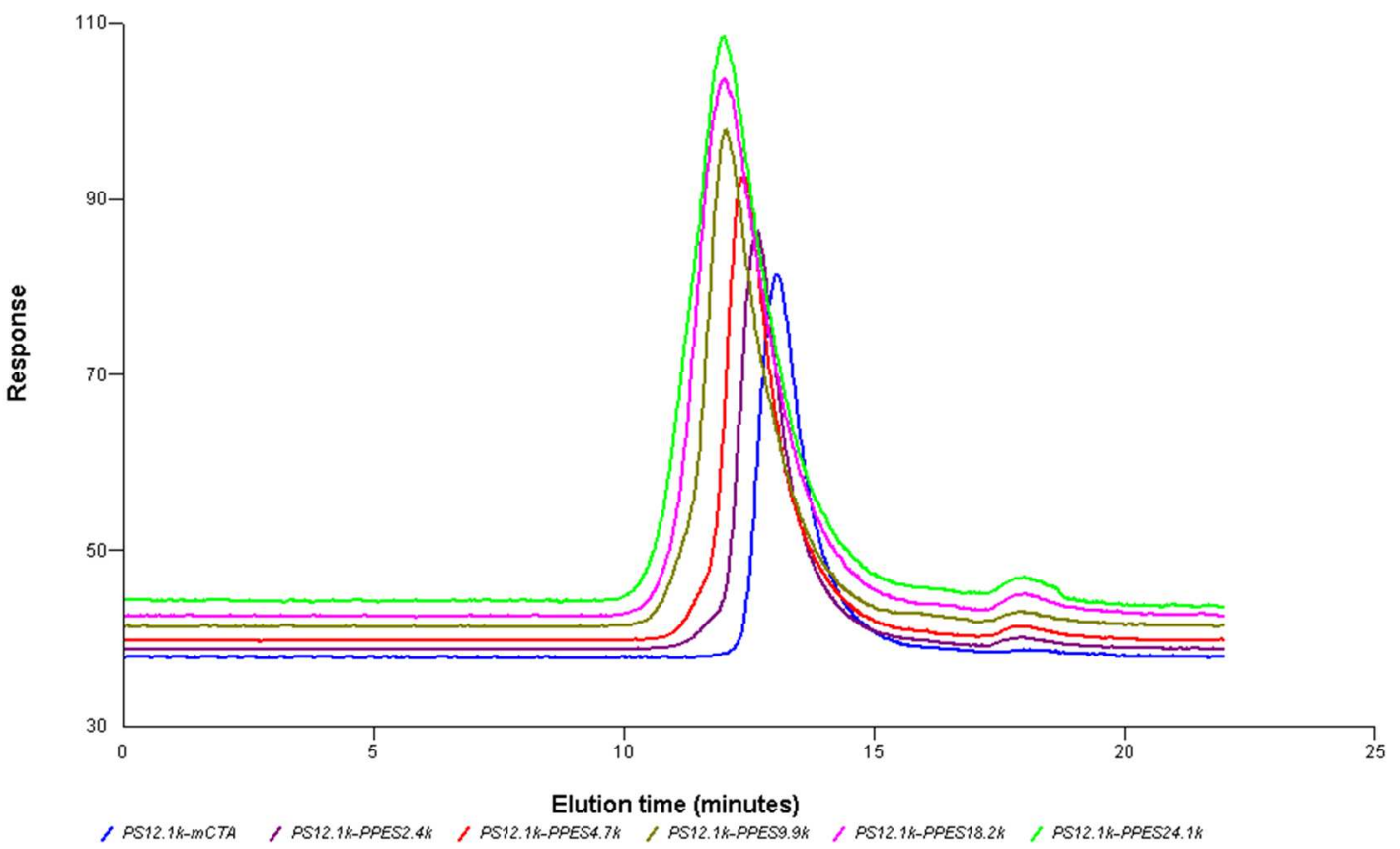

Figure S12. GPC traces of the $\mathrm{PS}_{116}$-series diblock copolymers. Eluent: THF. Flow rate: $1.0 \mathrm{~mL} / \mathrm{min}$. From bottom to top: $\mathrm{PS}_{116}$-CTA (blue), $\mathrm{PS}_{116}-\mathrm{PPES}_{12}$ (purple), $\mathrm{PS}_{116}-\mathrm{PPES}_{24}$ (red), $\mathrm{PS}_{116}-\mathrm{PPES}_{48}$ (dark khaki), $\mathrm{PS}_{116}-\mathrm{PPES}_{90}$ (violet red), $\mathrm{PS}_{116}-\mathrm{PPES}_{118}$ (light green). 
Table S1. Experimental data for $\mathrm{PS}_{\mathrm{x}}-\mathrm{PPES}_{\mathrm{y}}$ diblock copolymers prepared by RAFT polymerization from PS-CTAs ${ }^{\mathrm{a}}$

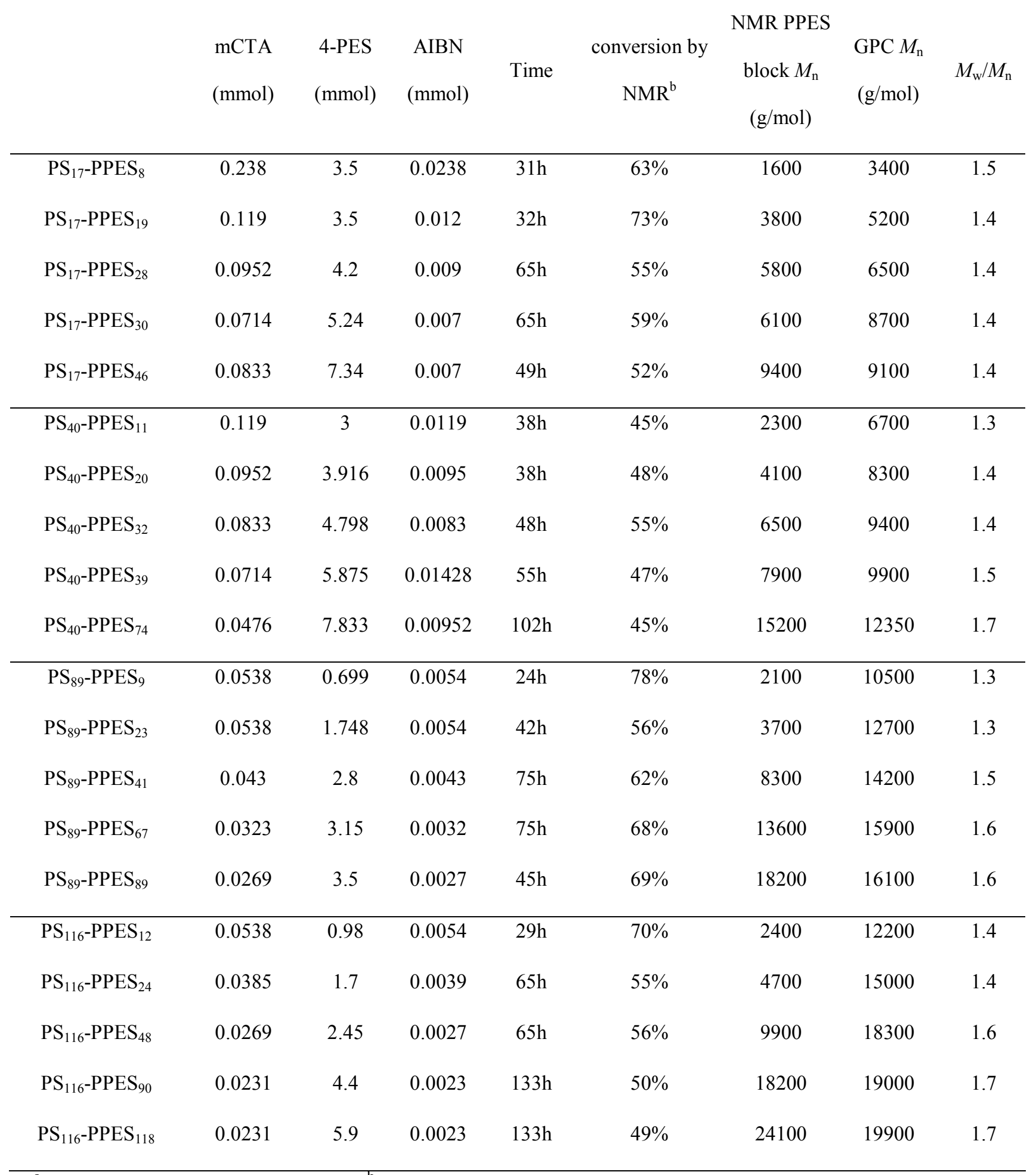

${ }^{a}$ All reactions were run at $90{ }^{\circ} \mathrm{C} .{ }^{b}$ Conversion calculation described on p. 11 of SI 


\section{Method used to calculate PES conversion and PS-PPES $M_{n}$ by ${ }^{1} \mathrm{H}$ NMR.}

Sample $\mathrm{PS}_{89}-\mathrm{PPES}_{41}$ is described as an example. To determine conversion during polymerization, approximately $0.05 \mathrm{ml}$ of the reaction mixture was taken out by syringe under positive nitrogen pressure, dissolved in $\mathrm{CDCl}_{3}(1 \mathrm{~mL})$, and examined by ${ }^{1} \mathrm{H}$ NMR. A sample was withdrawn immediately after beginning the polymerization (to ensure complete dissolution of polymerization components) and additional samples were withdrawn over the course of the polymerization. A typical ${ }^{1} \mathrm{H}$ NMR spectrum of the $\mathrm{PS}_{89}-\mathrm{PPES}_{41}$ polymerization mixture is shown in Figure S5. When the conversion reached 62\% (75 h, Table S1, Figure S6), the reaction was stopped.

To determine conversion, DMF was used as an internal standard and the normalized integrated area of the PPES vinylic protons ( $\delta 5.3$ or $5.8 \mathrm{ppm}$ ) in each sample was compared to the normalized integrated area of these peaks in the spectrum acquired for the sample taken at the start of the polymerization. It was assumed that the evaporative loss of DMF (b.p. $152{ }^{\circ} \mathrm{C}$ ) is negligible at the reaction temperature of $90{ }^{\circ} \mathrm{C} .{ }^{7-9}$ In each NMR spectrum, the integration of the $\mathrm{N}\left(\mathrm{CH}_{3}\right)_{2}$ peak at $(\delta 2.9 \mathrm{ppm})$ was set to a value of 6.00 . The integrated area under one $\mathrm{H}_{2} \mathrm{C}=$ peak ( $\delta 5.3$ or $5.8 \mathrm{ppm}$ ) was then compared to that in the initial spectrum taken. In the examples shown (Figures S5-S6), the peak at $5.3 \mathrm{ppm}$ integrates to 9.46 in the initial spectrum and to 3.59 in the final reaction mixture. Assuming that all monomer that is lost from the reaction mixture is converted to polymer, the calculated conversion by NMR is: $(9.46-3.59) / 9.46=0.62$. This method was used for all reported conversion values. ${ }^{7-9}$ The calculated conversion value was used to calculate $M_{\mathrm{n}}$ by eqn (1).

$M_{\mathrm{n}, \mathrm{NMR}}=\frac{[\text { Monomer }]}{[C T A]} * M W(M) * p+M W(C T A)$

$M W(M)$ is the molecular weight of 4-PES and $M W(C T A)$ is the molecular weight of the CTA; [Monomer] and [CTA] are concentrations of monomer and CTA, $p$ is the conversion calculated from NMR integration 


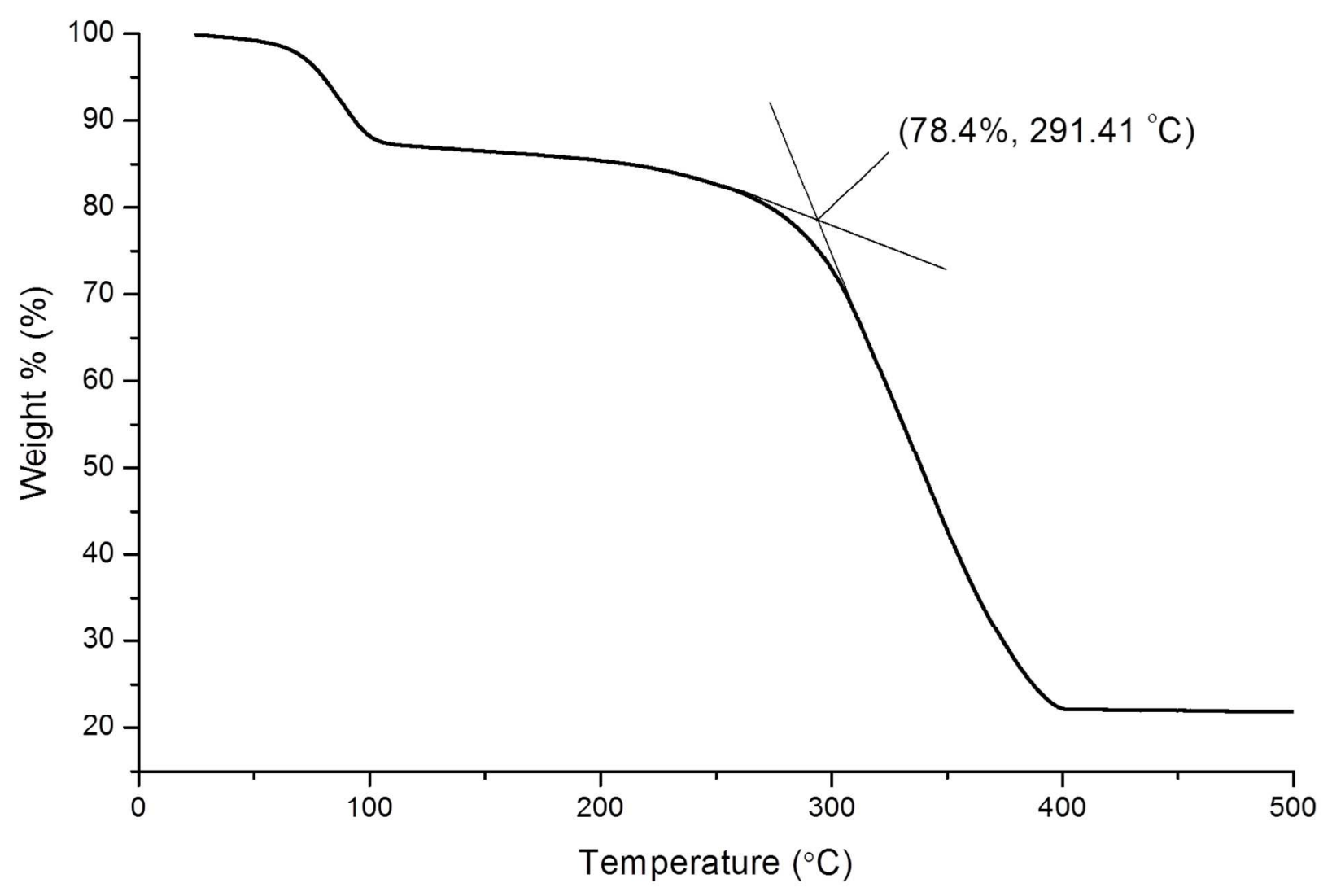

Figure S13. TGA $\left(1{ }^{\circ} \mathrm{C} / \mathrm{min}, \mathrm{N}_{2}\right.$ atmosphere $)$ curve of a representative sample: $\mathrm{PS}_{89^{-}}$ $\mathrm{PPES}_{41}\left[\mathrm{Co}_{2}(\mathrm{CO})_{6}\right]_{36}$. 
Table S2. Summary of TGA data for PS-PPES/Co block copolymers

\begin{tabular}{|c|c|c|c|}
\hline \multicolumn{4}{|c|}{ PS1.8k copolymers } \\
\hline Molecular formula & CO $\%$ by TGA & $\mathrm{Co}_{2}(\mathrm{CO})_{6}$ units & $\% f^{\mathrm{a}}$ \\
\hline $\mathrm{PS}_{17}-\mathrm{PPES}_{8}\left[\mathrm{Co}_{2}(\mathrm{CO})_{6}\right]_{8}$ & $22.9 \%$ & 8 & 95 \\
\hline $\mathrm{PS}_{17}-\mathrm{PPES}_{19}\left[\mathrm{Co}_{2}(\mathrm{CO})_{6}\right]_{16}$ & $26.2 \%$ & 16 & 84 \\
\hline $\mathrm{PS}_{17}-\mathrm{PPES}_{28}\left[\mathrm{Co}_{2}(\mathrm{CO})_{6}\right]_{24}$ & $27.9 \%$ & 24 & 86 \\
\hline $\mathrm{PS}_{17}-\mathrm{PPES}_{30}\left[\mathrm{Co}_{2}(\mathrm{CO})_{6}\right]_{25}$ & $27.7 \%$ & 25 & 82 \\
\hline $\mathrm{PS}_{17}-\mathrm{PPES}_{46}\left[\mathrm{Co}_{2}(\mathrm{CO})_{6}\right]_{38}$ & $28.9 \%$ & 38 & 82 \\
\hline \multicolumn{4}{|c|}{ PS4.2k copolymers } \\
\hline $\mathrm{PS}_{40}-\mathrm{PPES}_{11}\left[\mathrm{Co}_{2}(\mathrm{CO})_{6}\right]_{11}$ & $18.7 \%$ & 11 & 97 \\
\hline $\mathrm{PS}_{40}-\mathrm{PPES}_{20}\left[\mathrm{Co}_{2}(\mathrm{CO})_{6}\right]_{18}$ & $22.3 \%$ & 18 & 88 \\
\hline $\mathrm{PS}_{40}-\mathrm{PPES}_{32}\left[\mathrm{Co}_{2}(\mathrm{CO})_{6}\right]_{28}$ & $25.1 \%$ & 28 & 87 \\
\hline $\mathrm{PS}_{40}-\mathrm{PPES}_{39}\left[\mathrm{Co}_{2}(\mathrm{CO})_{6}\right]_{33}$ & $25.7 \%$ & 33 & 84 \\
\hline $\mathrm{PS}_{40}-\mathrm{PPES}_{74}\left[\mathrm{Co}_{2}(\mathrm{CO})_{6}\right]_{62}$ & $28.1 \%$ & 62 & 84 \\
\hline \multicolumn{4}{|c|}{ PS9.3k copolymers } \\
\hline $\mathrm{PS}_{89}-\mathrm{PPES}_{9}\left[\mathrm{Co}_{2}(\mathrm{CO})_{6}\right]_{8}$ & $10.2 \%$ & 8 & 91 \\
\hline $\mathrm{PS}_{89}-\mathrm{PPES}_{23}\left[\mathrm{Co}_{2}(\mathrm{CO})_{6}\right]_{21}$ & $17.6 \%$ & 21 & 91 \\
\hline $\mathrm{PS}_{89}-\mathrm{PPES}_{41}\left[\mathrm{Co}_{2}(\mathrm{CO})_{6}\right]_{36}$ & $21.7 \%$ & 36 & 87 \\
\hline $\mathrm{PS}_{89}-\mathrm{PPES}_{67}\left[\mathrm{Co}_{2}(\mathrm{CO})_{6}\right]_{56}$ & $24.1 \%$ & 56 & 83 \\
\hline $\mathrm{PS}_{89}-\mathrm{PPES}_{89}\left[\mathrm{Co}_{2}(\mathrm{CO})_{6}\right]_{79}$ & $26.6 \%$ & 79 & 89 \\
\hline \multicolumn{4}{|c|}{ PS12.1k copolymers } \\
\hline $\mathrm{PS}_{116}-\mathrm{PPES}_{12}\left[\mathrm{Co}_{2}(\mathrm{CO})_{6}\right]_{11}$ & $10.6 \%$ & 11 & 93 \\
\hline $\mathrm{PS}_{116}-\mathrm{PPES}_{24}\left[\mathrm{Co}_{2}(\mathrm{CO})_{6}\right]_{23}$ & $16.7 \%$ & 23 & 97 \\
\hline $\mathrm{PS}_{116}-\mathrm{PPES}_{48}\left[\mathrm{Co}_{2}(\mathrm{CO})_{6}\right]_{43}$ & $21.2 \%$ & 43 & 90 \\
\hline $\mathrm{PS}_{116}-\mathrm{PPES}_{90}\left[\mathrm{Co}_{2}(\mathrm{CO})_{6}\right]_{84}$ & $26.0 \%$ & 84 & 93 \\
\hline $\mathrm{PS}_{116}-\mathrm{PPES}_{118}\left[\mathrm{Co}_{2}(\mathrm{CO})_{6}\right]_{110}$ & $27.4 \%$ & 110 & 93 \\
\hline
\end{tabular}

\footnotetext{
${ }^{a}$ Estimated percent functionalization of alkyne groups $(\% f)$ by method described on p. 14 of SI.
} 


\section{Calculation of percent functionalization (\%f) of alkyne groups with cobalt carbonyl from TGA data:}

For each $\mathrm{PS}_{\mathrm{x}}-\mathrm{PPES}_{\mathrm{y}}\left[\mathrm{Co}_{2}(\mathrm{CO})_{6}\right]_{\mathrm{n}}$ adduct, the weight fraction of carbon monoxide $\left(f_{\mathrm{CO}}\right)$ as measured from TGA data can be expressed as:

$f_{C O}=\frac{n \times 6 m[\mathrm{CO}]}{M_{n}+m\left[\mathrm{Co}_{2}(\mathrm{CO})_{6}\right] \times n}=\frac{n \times 168.06}{M_{n}+285.626 \times n}$

where $n$ is the average number of alkyne groups per chain that have reacted with cobalt carbonyl, $m[\mathrm{CO}]$ is the molar mass of $\mathrm{CO}, M_{n}$ is the number-average molecular weight of the PS-PPES diblock copolymer determined prior to reaction with cobalt carbonyl, and $m\left[\mathrm{Co}_{2}(\mathrm{CO})_{6}\right]$ is the molar mass of the dicobalt hexacarbonyl moieties bound to the polymer. Solving equation (2) for $n$ allows it to be estimated from the known estimates of $M_{\mathrm{n}}$ and $f_{\mathrm{CO}}$ for each polymer:

$n=\frac{M_{n} \times f_{\mathrm{CO}}}{168.06-285.626 \times f_{\mathrm{CO}}}$

$\%$ Functionalization $(\% f)$ is defined as:

$\% f=100 \times n / y$

where $y$ is the average number of PPES units in each polymer chain. 


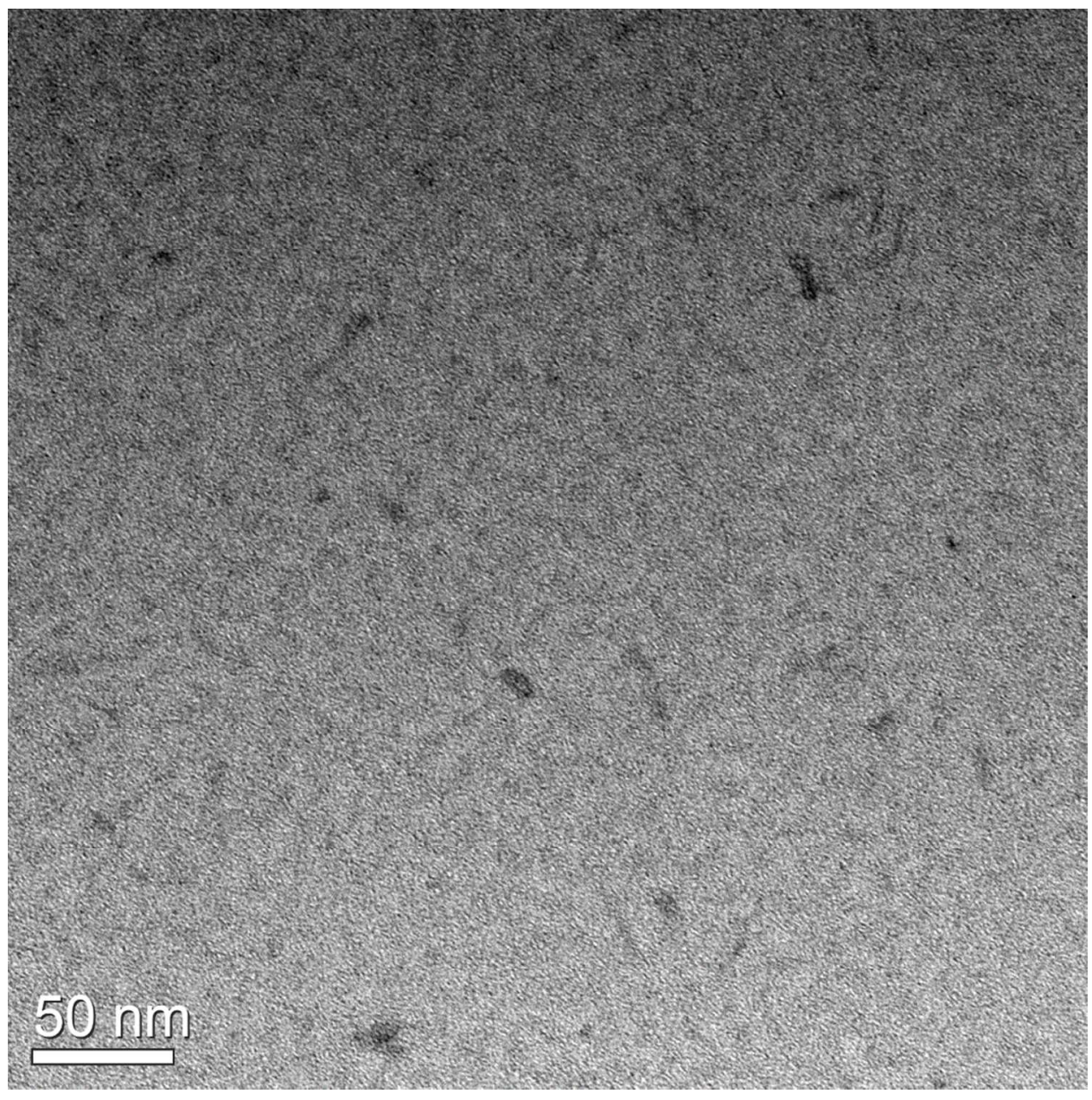

Figure S14. Representative TEM image of sample $\mathrm{PS}_{116}-\mathrm{PPES}_{12}\left[\mathrm{Co}_{2}(\mathrm{CO})_{6}\right]_{11}\left(f_{\mathrm{PS}}=0.68\right)$ at $50,000 \times$ magnification. 


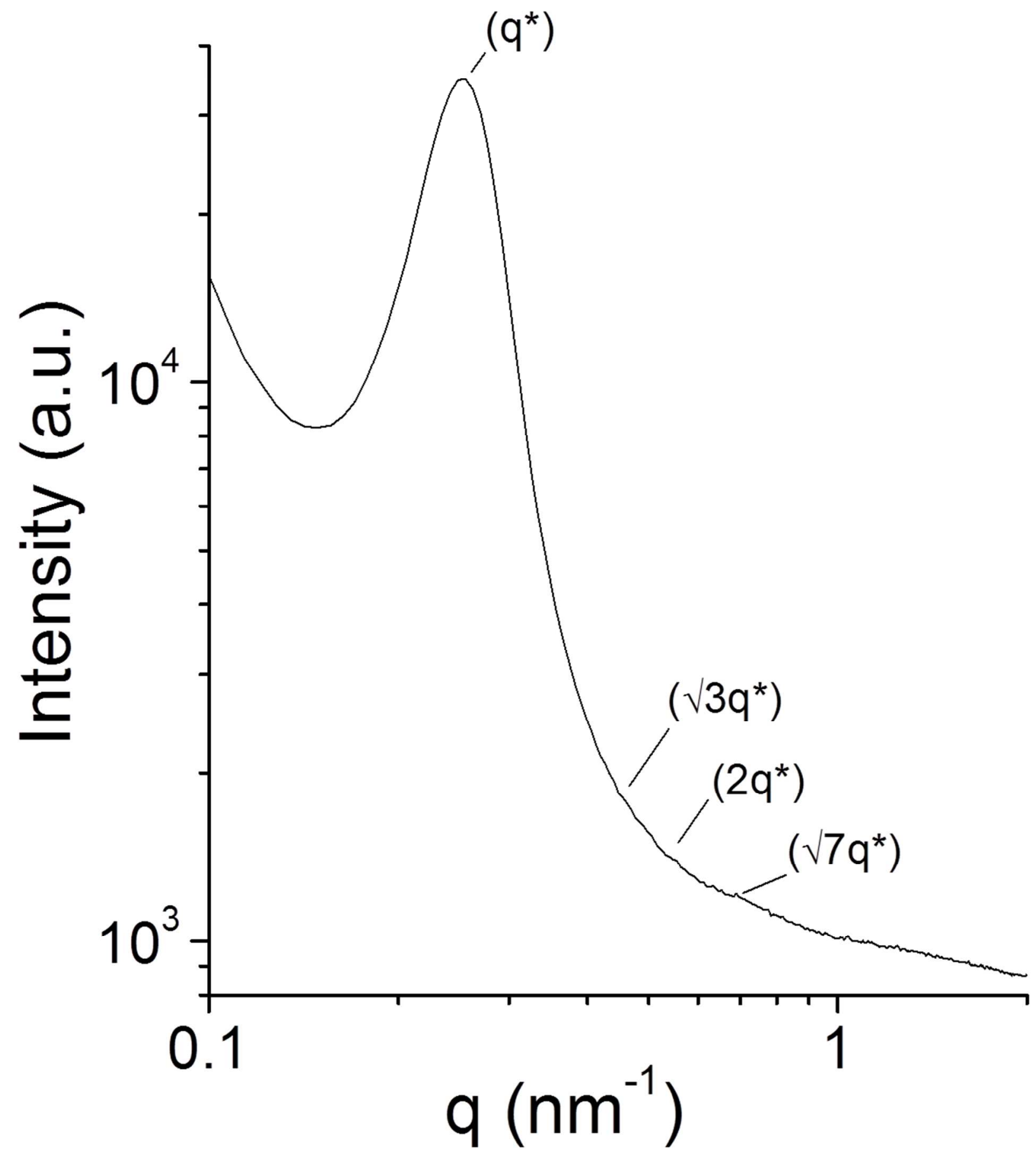

Figure S15. Enlarged SAXS profile for sample $\mathrm{PS}_{89}-\mathrm{PPES}_{67}\left[\mathrm{Co}_{2}(\mathrm{CO})_{6}\right]_{56}$. Peaks spanning $\sqrt{ } 3 \mathrm{q}$ to $2 q$, and at $\sqrt{7} q$ are visible. 


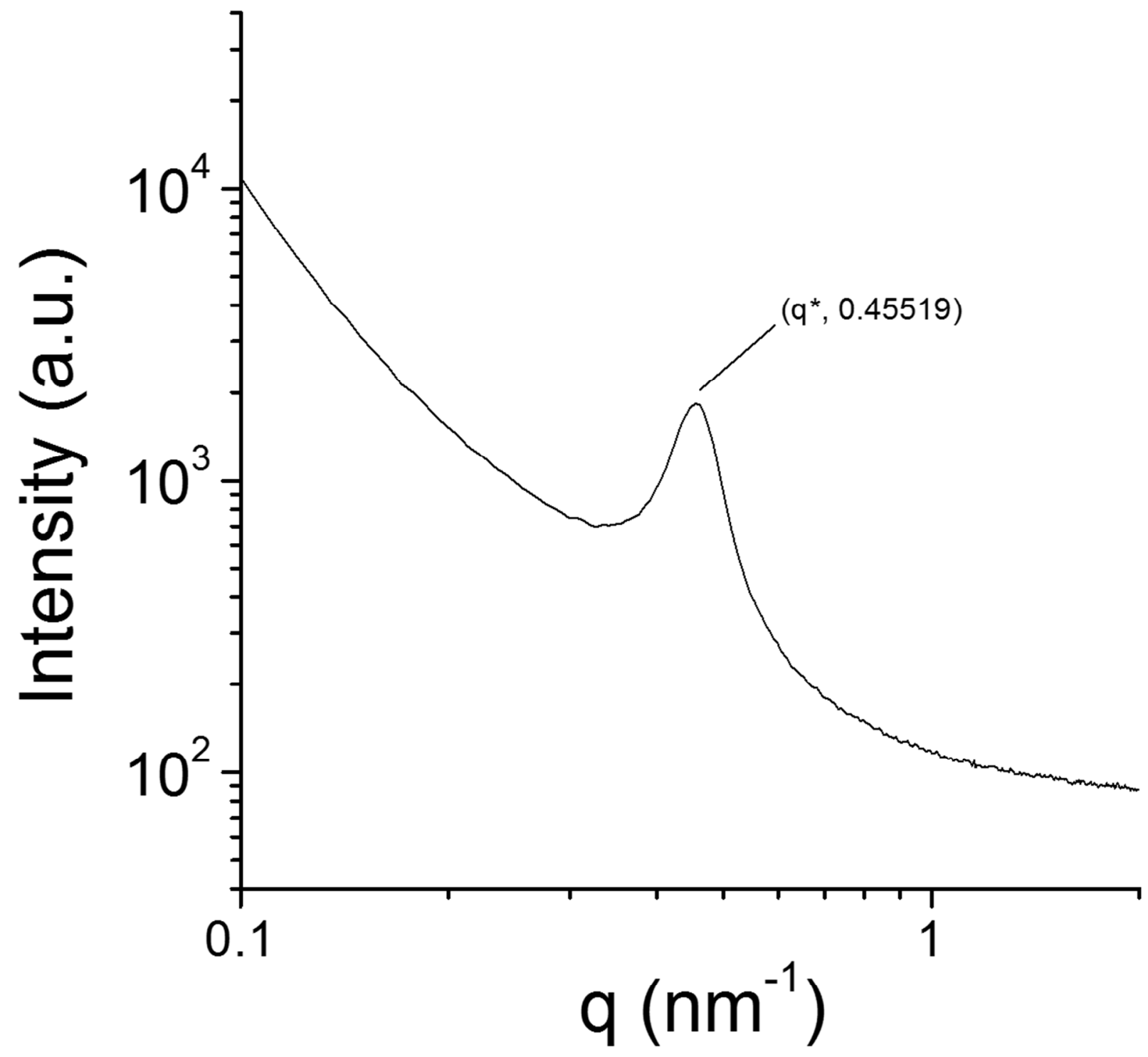

Figure S16. SAXS profile of sample of $\mathrm{PS}_{40}-\mathrm{PPES}_{11}\left[\mathrm{Co}_{2}(\mathrm{CO})_{6}\right]_{11}$. Only one weak scattering peak is observed. 


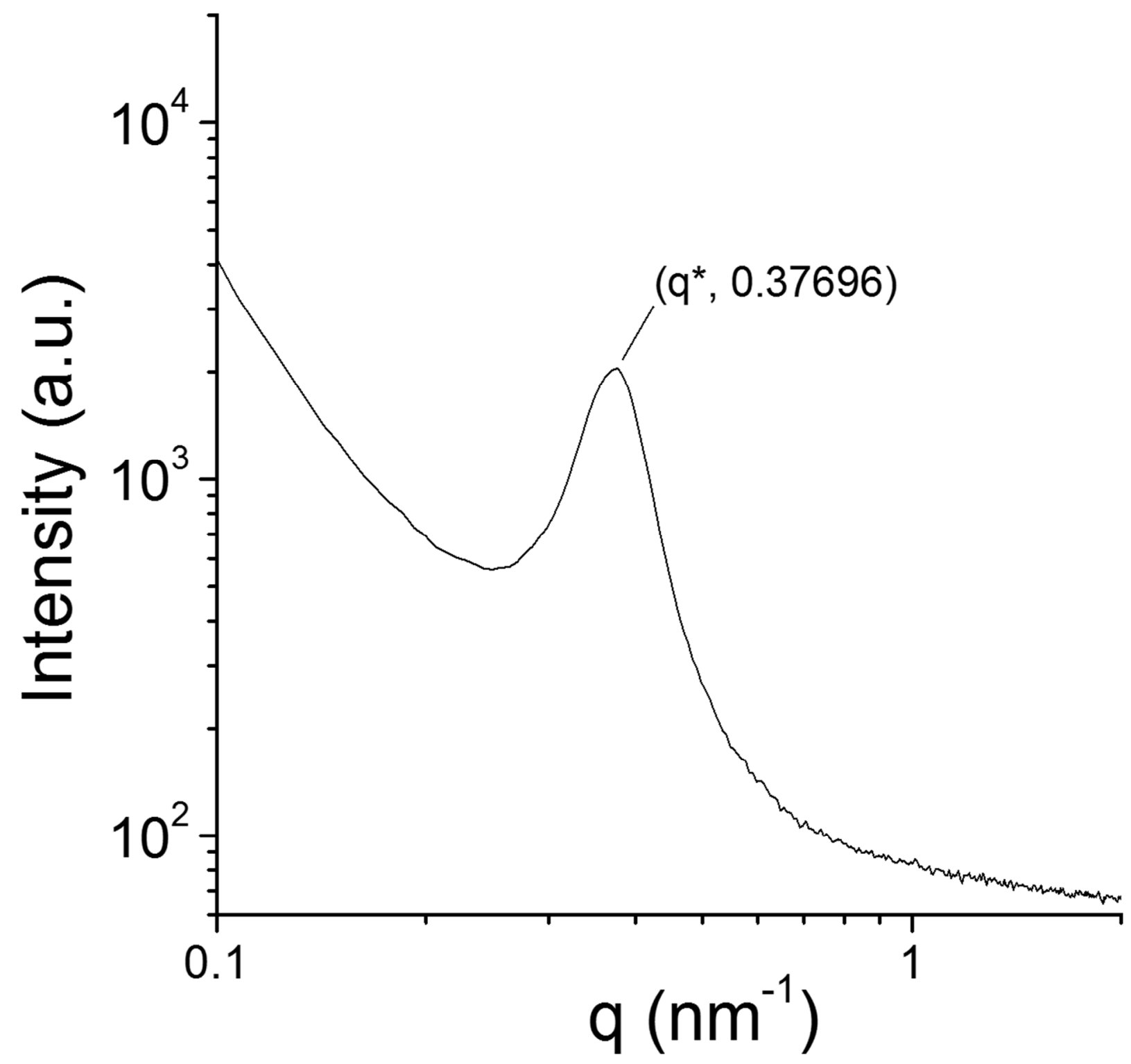

Figure S17. SAXS profile of sample $\mathrm{PS}_{40}-\mathrm{PPES}_{20}\left[\mathrm{Co}_{2}(\mathrm{CO})_{6}\right]_{18}$. 


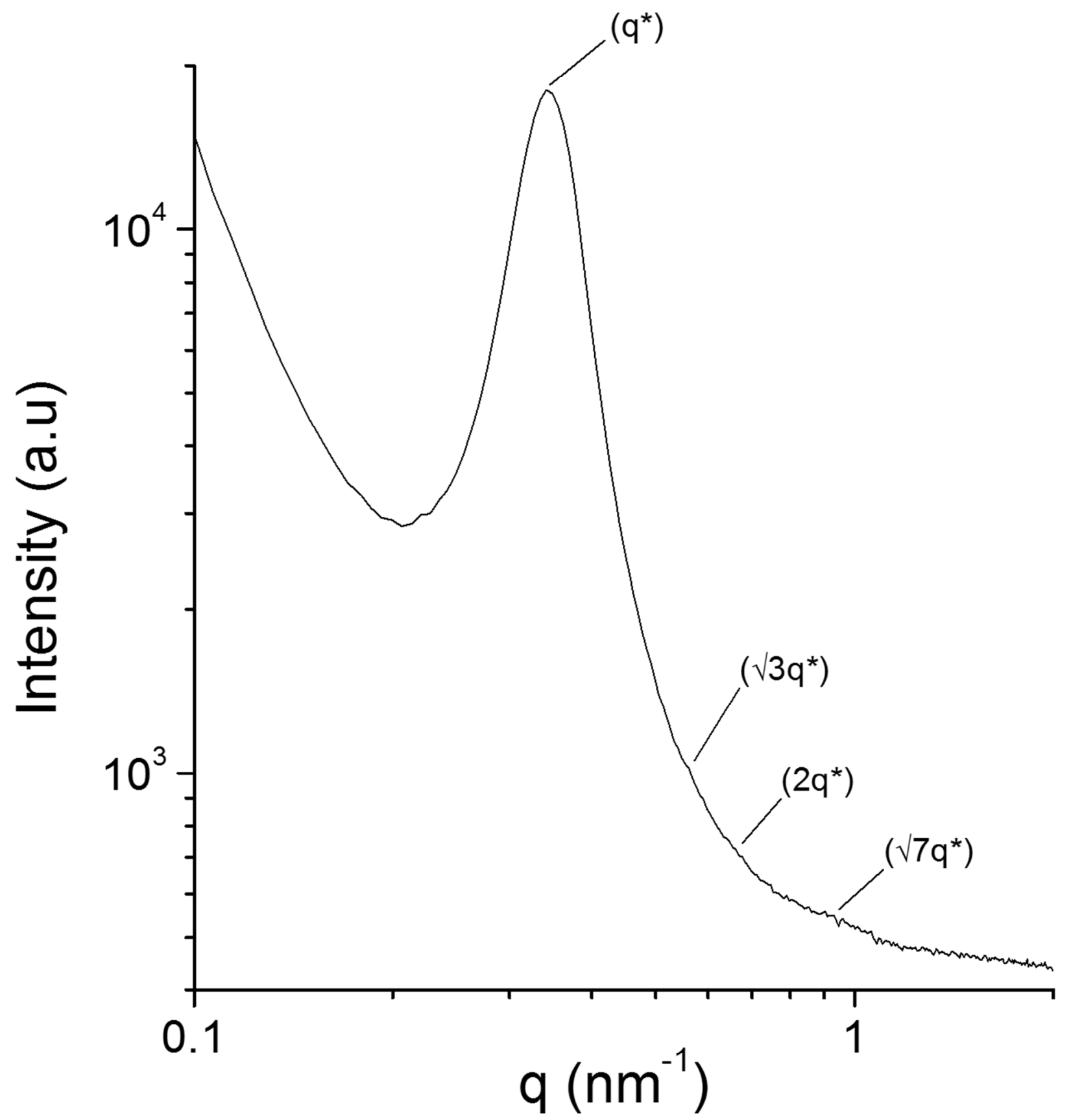

Figure S18. SAXS profile of sample $\mathrm{PS}_{40}-\mathrm{PPES}_{32}\left[\mathrm{Co}_{2}(\mathrm{CO})_{6}\right]_{28}$. Peaks at $q^{*}, \sqrt{ } 3 q^{*}, 2 q^{*}$ and $\sqrt{ } 7 q^{*}$ are visible. 


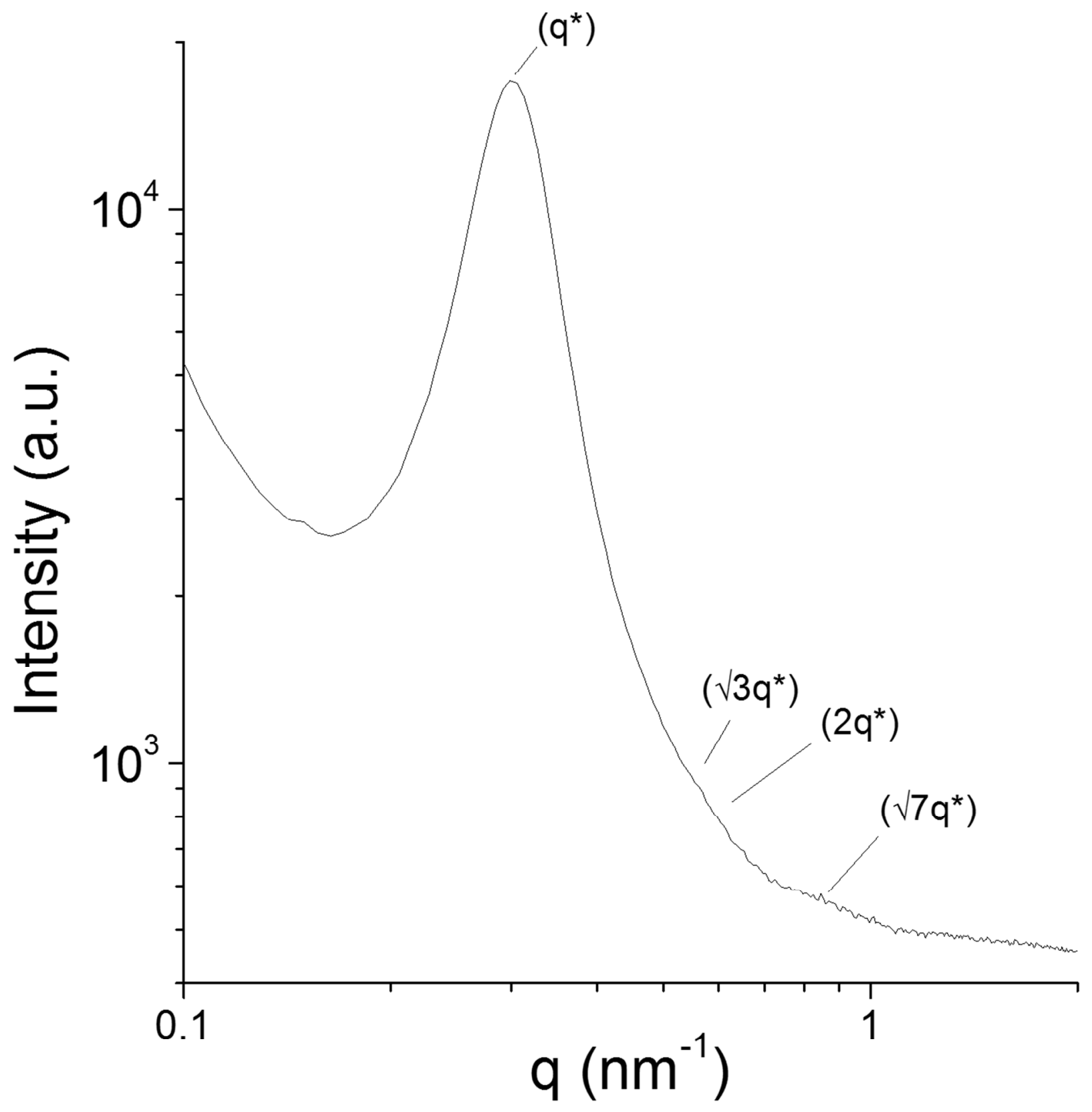

Figure S19. SAXS profile of sample $\mathrm{PS}_{40}-\mathrm{PPES}_{39}\left[\mathrm{Co}_{2}(\mathrm{CO})_{6}\right]_{33}$. Peaks at $q^{*}$, spanning $\sqrt{3} q^{*}-2 q^{*}$, and $\sqrt{ } 7 q^{*}$. 


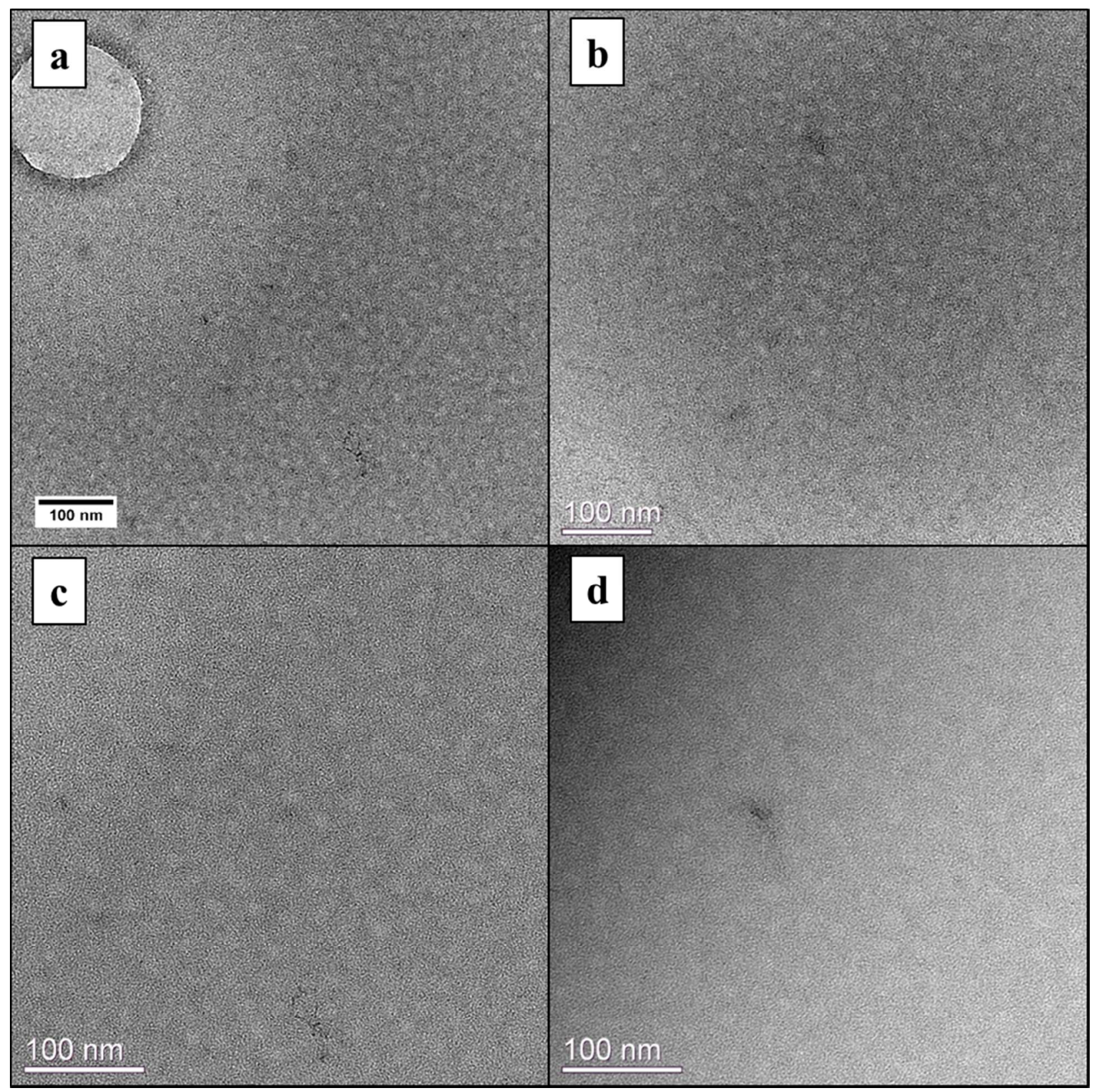

Figure S20. TEM images showing spherical morphology of sample $\mathrm{PS}_{40}-\mathrm{PPES}_{74}\left[\mathrm{Co}_{2}(\mathrm{CO})_{6}\right]_{62}$ block copolymers as cast from toluene solutions (5-10 mg polymer/mL toluene) onto carboncoated copper grids: (a) 25,000×; (b) 30,000×; (c), (d) both 40,000×. 


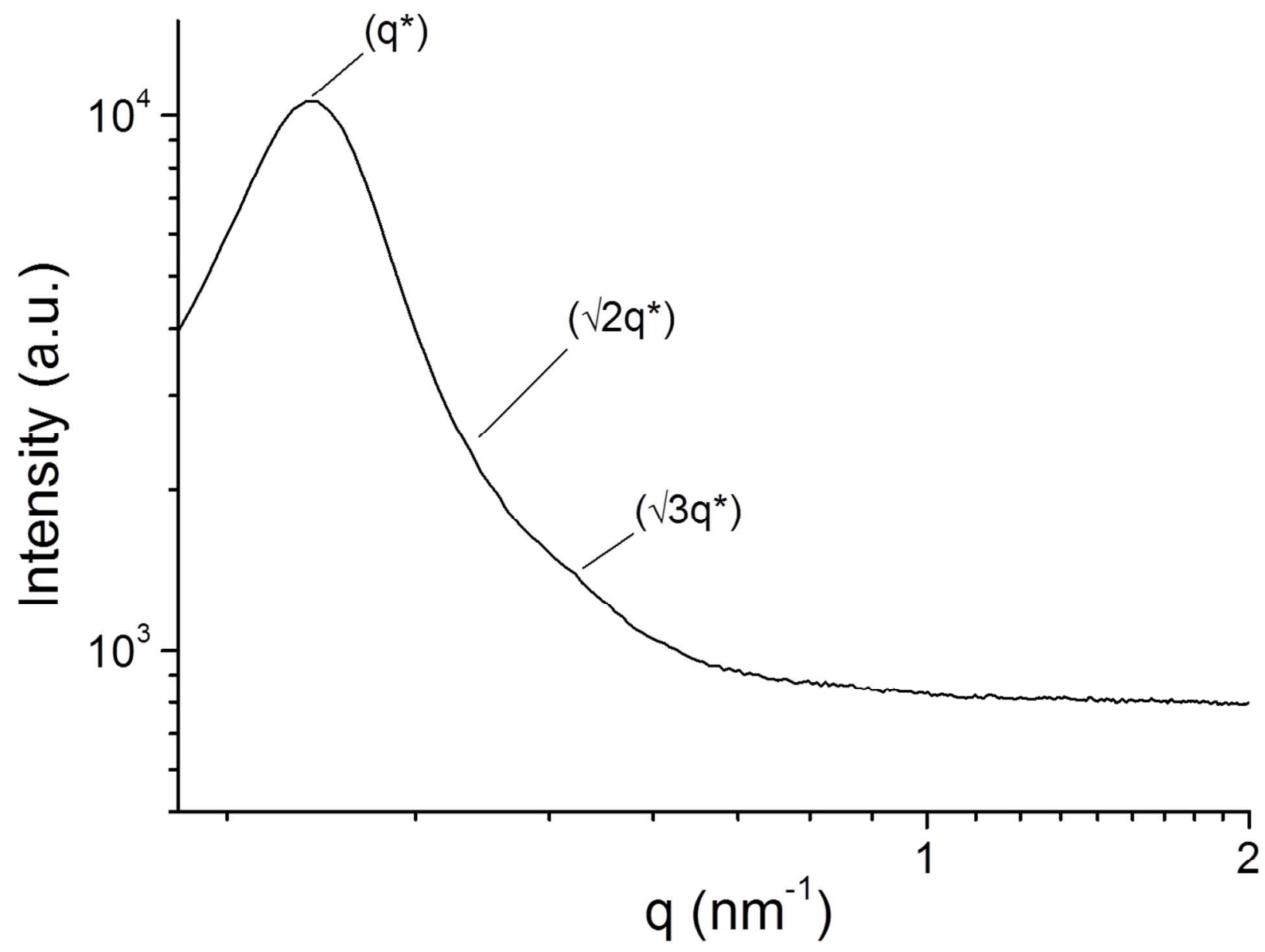

Figure S21. SAXS profile of sample $\mathrm{PS}_{40}-\mathrm{PPES}_{74}\left[\mathrm{Co}_{2}(\mathrm{CO})_{6}\right]_{62}$. 


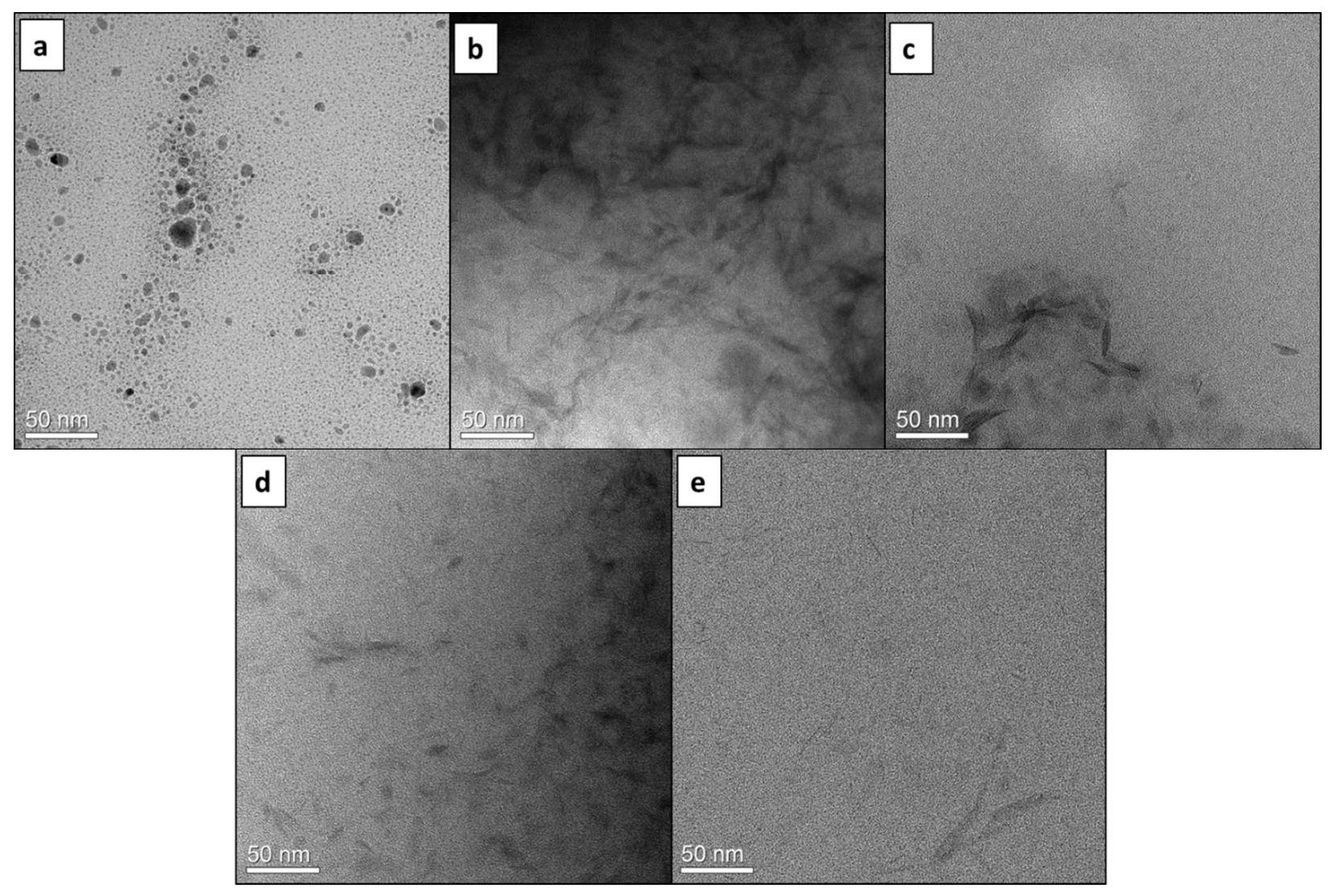

Figure S22. TEM images of $\mathrm{PS}_{17}$-series: (a) $\mathrm{PS}_{17}-\mathrm{PPES}_{8}\left[\mathrm{Co}_{2}(\mathrm{CO})_{6}\right]_{8}$; (b) $\mathrm{PS}_{17-}$ $\mathrm{PPES}_{19}\left[\mathrm{Co}_{2}(\mathrm{CO})_{6}\right]_{16}$; (c) $\mathrm{PS}_{17}-\mathrm{PPES}_{28}\left[\mathrm{Co}_{2}(\mathrm{CO})_{6}\right]_{24}$; (d) $\mathrm{PS}_{17}-\mathrm{PPES}_{30}\left[\mathrm{Co}_{2}(\mathrm{CO})_{6}\right]_{25}$ : (e) $\mathrm{PS}_{17-}$ $\mathrm{PPES}_{46}\left[\mathrm{Co}_{2}(\mathrm{CO})_{6}\right]_{38}$. 


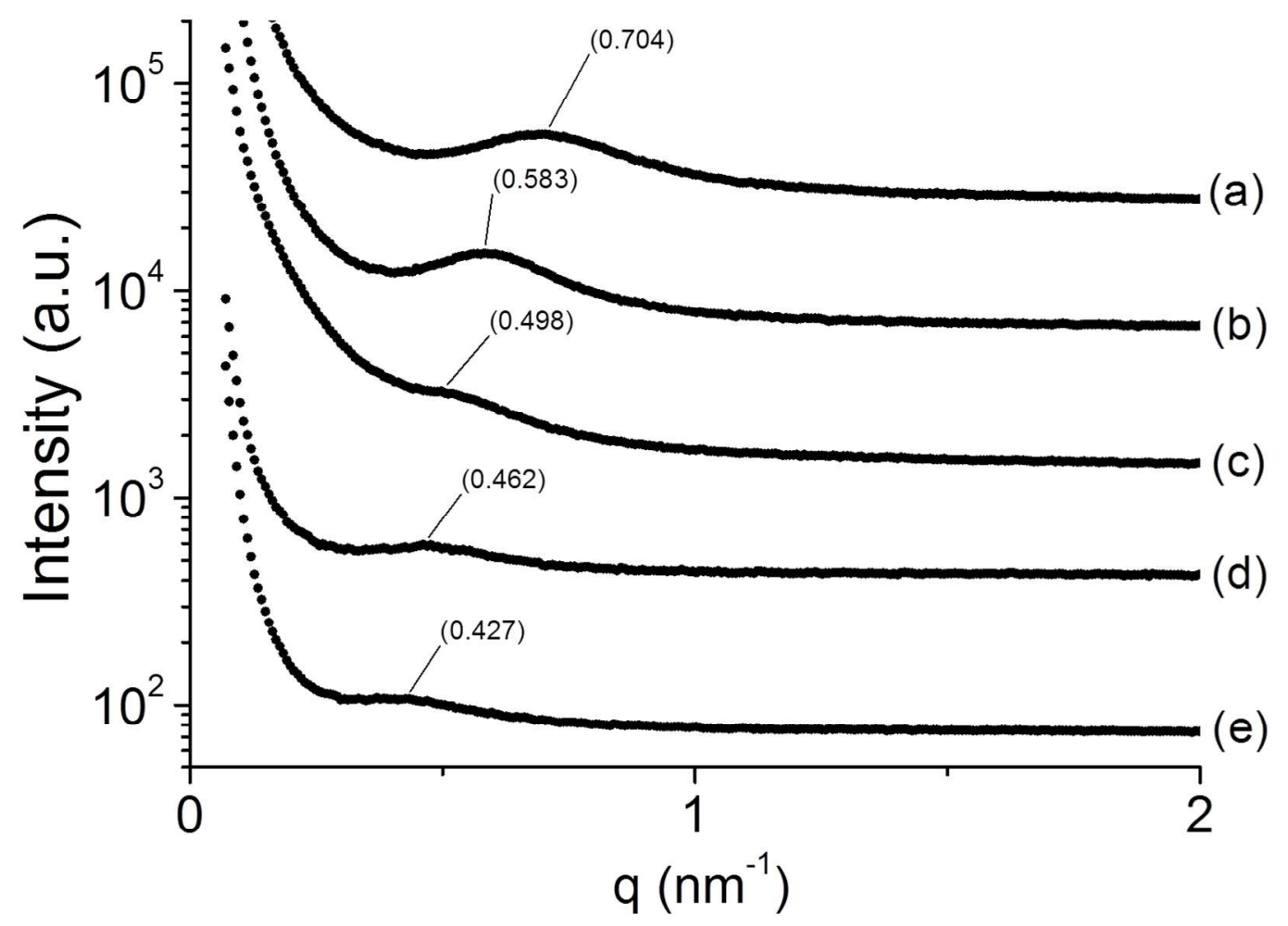

Figure S23. SAXS profiles of samples in the $\mathrm{PS}_{17}$-series. (a) $\mathrm{PS}_{17}-\mathrm{PPES}_{8}\left[\mathrm{Co}_{2}(\mathrm{CO})_{6}\right]_{8}$; (b) $\mathrm{PS}_{17}$ $\mathrm{PPES}_{19}\left[\mathrm{Co}_{2}(\mathrm{CO})_{6}\right]_{16}$; (c) $\mathrm{PS}_{17}-\mathrm{PPES}_{28}\left[\mathrm{Co}_{2}(\mathrm{CO})_{6}\right]_{24}$; (d) $\mathrm{PS}_{17}-\mathrm{PPES}_{30}\left[\mathrm{Co}_{2}(\mathrm{CO})_{6}\right]_{25}$ : (e) $\mathrm{PS}_{17^{-}}$ $\mathrm{PPES}_{46}\left[\mathrm{Co}_{2}(\mathrm{CO})_{6}\right]_{38}$. 


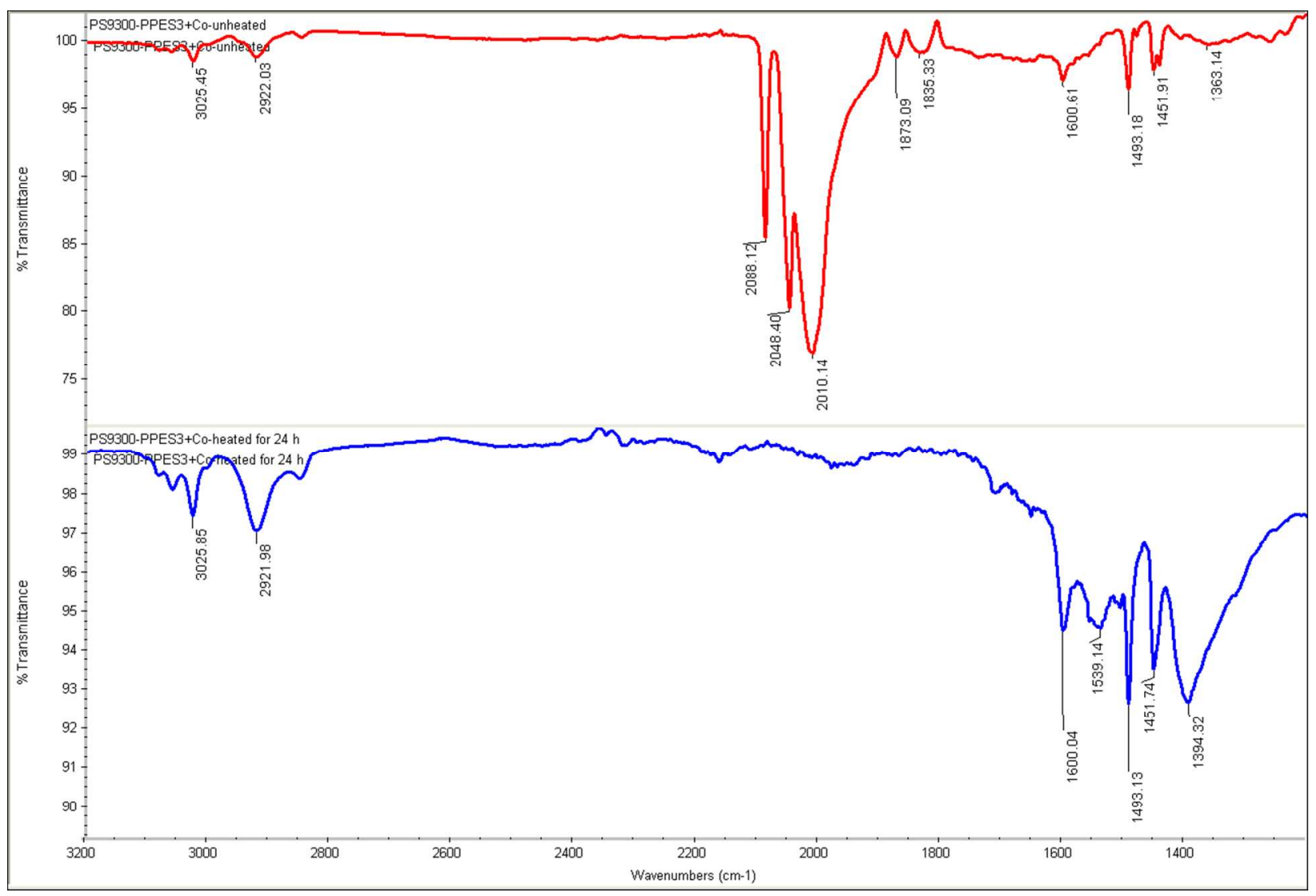

Figure S24. Comparative IR spectrum for $\mathrm{PS}_{89}-\mathrm{PPES}_{41}\left[\mathrm{Co}_{2}(\mathrm{CO})_{6}\right]_{36}$ before (red) and after (blue) being heated at $120^{\circ} \mathrm{C}$ for 24 hours. The disappearance of the peaks corresponding to Co-ligated $\mathrm{CO}$ at 2010, 2048, and $2088 \mathrm{~cm}^{-1}$ after heating indicate the formation of cobalt nanoparticles. 


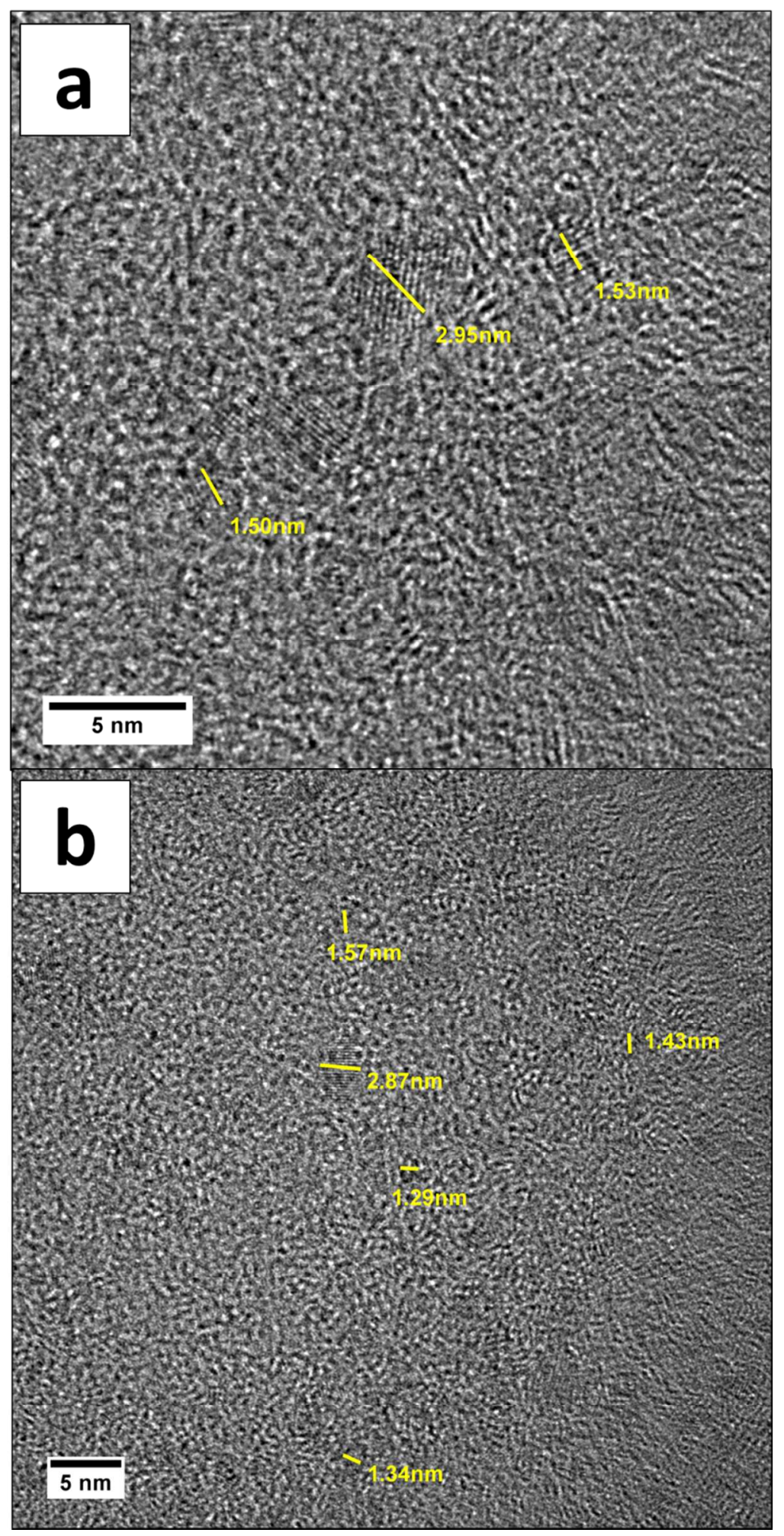

Figure S25. (a) Sample $\mathrm{PS}_{116}-\mathrm{PPES}_{48}\left[\mathrm{Co}_{2}(\mathrm{CO})_{6}\right]_{43}$, measured diameters of selected nanoparticles formed after heating at $120{ }^{\circ} \mathrm{C}$ for 24 hours under vacuum. (b) Sample PS ${ }_{89}-\mathrm{PPES}_{41}\left[\mathrm{Co}_{2}(\mathrm{CO})_{6}\right]_{36}$, measured diameters of selected nanoparticles formed after heating at $120{ }^{\circ} \mathrm{C}$ for 24 hours under vacuum. 

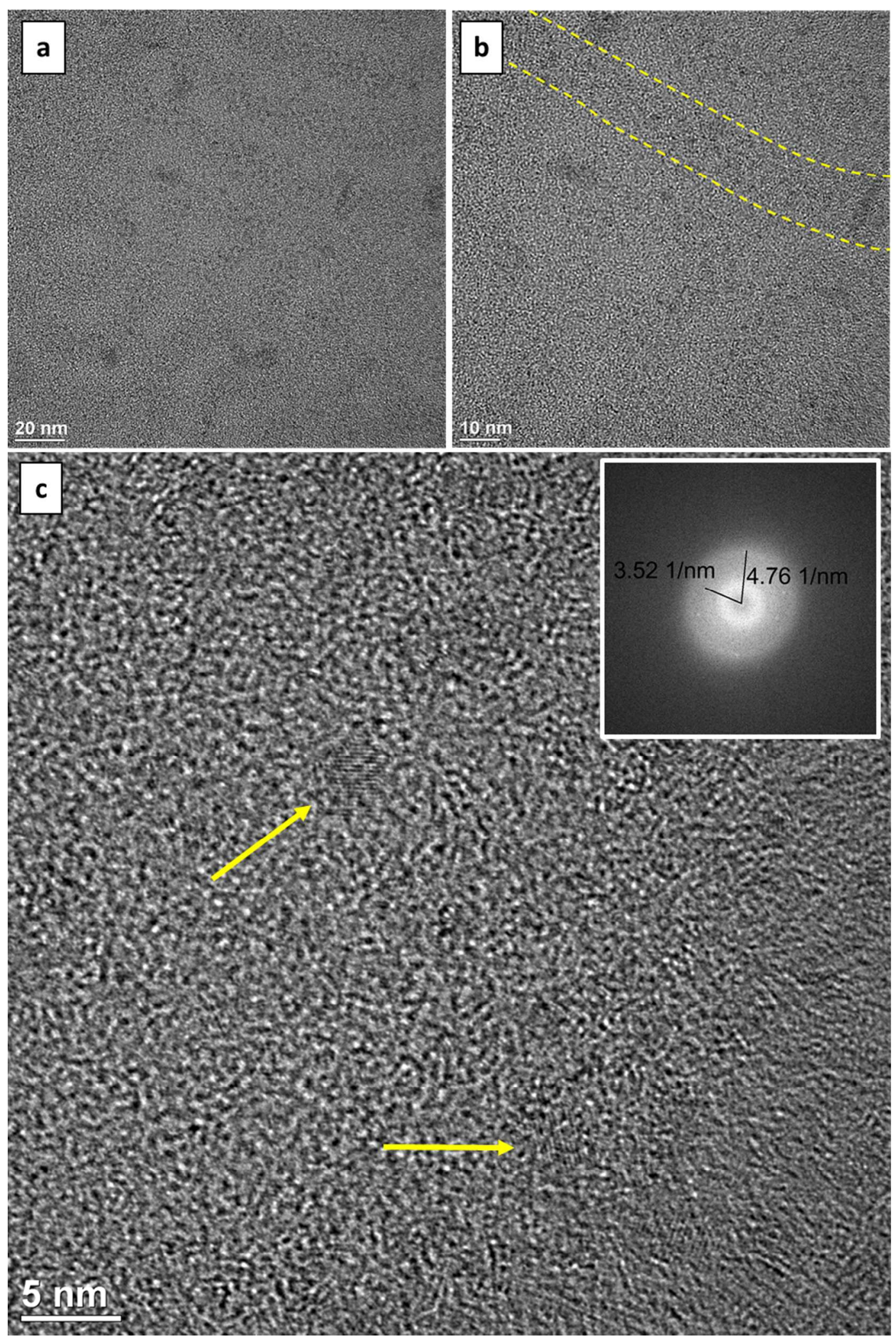

Figure S26. High magnification TEM images of $\mathrm{PS}_{89}-\mathrm{PPES}_{41}\left[\mathrm{Co}_{2}(\mathrm{CO})_{6}\right]_{36}$ samples after heating at $120{ }^{\circ} \mathrm{C}$ for $24 \mathrm{~h}$, demonstrating existence of nanoparticles in the -PPES/Co region. Inset in c: FFT of image $\mathrm{c}$. 

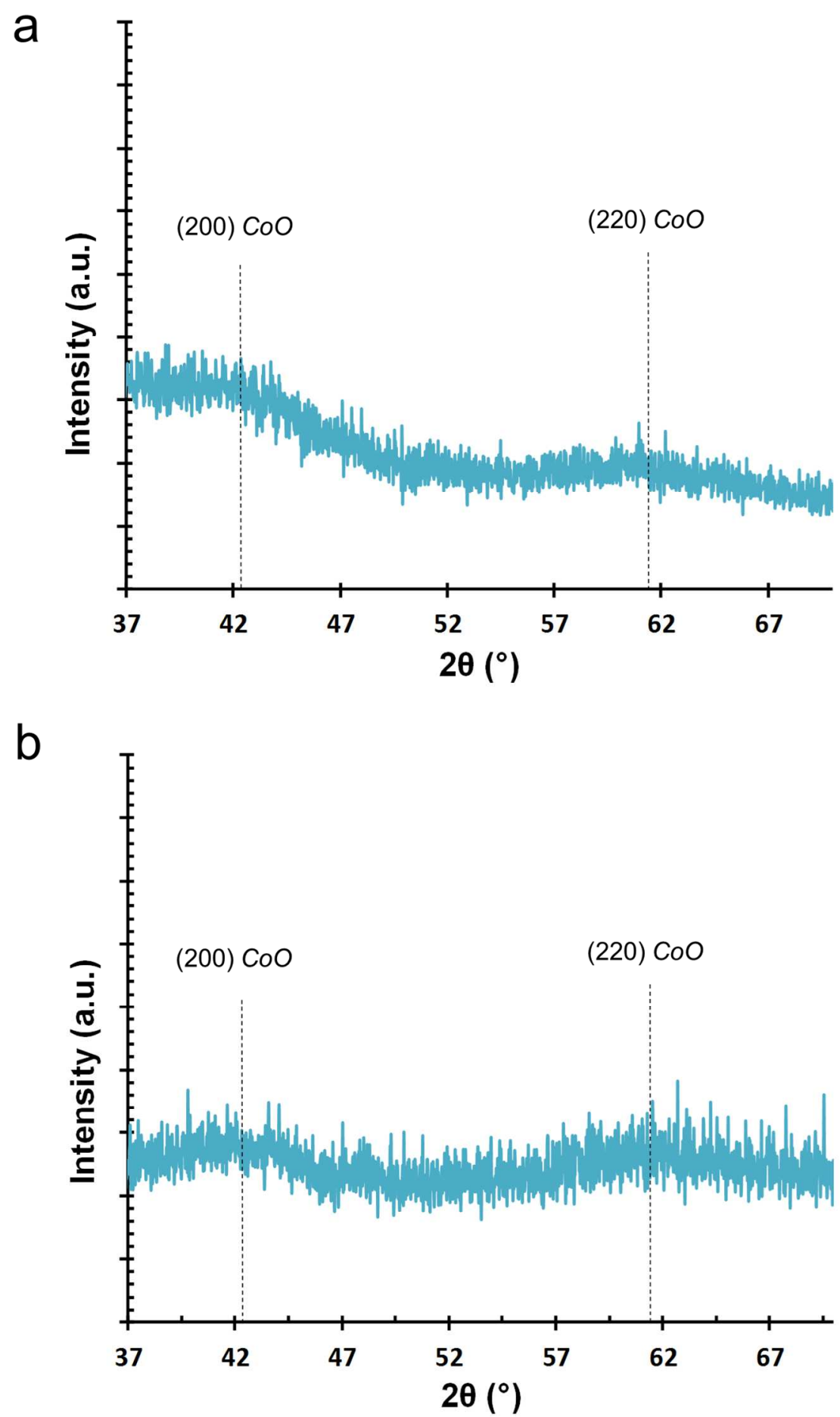

Figure S27. XRD of heated samples after heating at $120{ }^{\circ} \mathrm{C}$ for $24 \mathrm{~h}$. (a) $\mathrm{PS}_{116^{-}}$ $\mathrm{PPES}_{48}\left[\mathrm{Co}_{2}(\mathrm{CO})_{6}\right]_{43} ;$; (b) $\mathrm{PS}_{89}-\mathrm{PPES}_{41}\left[\mathrm{Co}_{2}(\mathrm{CO})_{6}\right]_{36}$. 

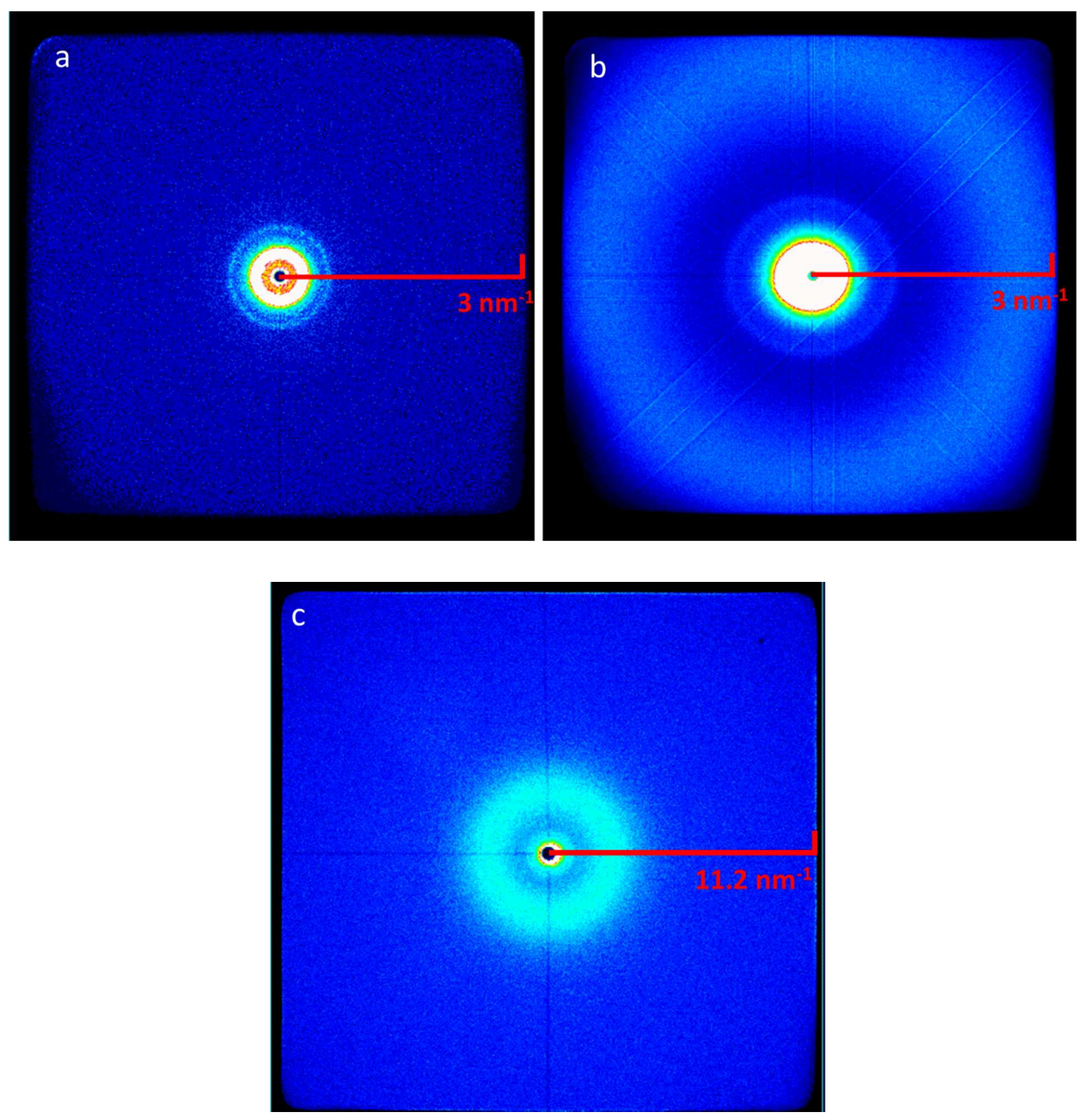

Figure S28. 2D SAXS patterns for sample $\mathrm{PS}_{116}-\mathrm{PPES}_{48}\left[\mathrm{Co}_{2}(\mathrm{CO})_{6}\right]_{43}$, at a sample-to-detector distance of $1077.7 \mathrm{~mm}\left(0<\mathrm{q}<3.5 \mathrm{~nm}^{-1}\right)$. (a) Sample prior to heating; (b) the same sample, after being heated at $120{ }^{\circ} \mathrm{C}$ for 24 hours. The broad peak near the edge of detector $\left(q \approx 2 \mathrm{~nm}^{-1}\right)$, indicates the formation of nanoparticles. ${ }^{10}$ (c) The same sample, after heating, at a shorter sample-to-detector distance $(277.2 \mathrm{~mm})$ where the nanoparticle scattering ring can be fully observed. 

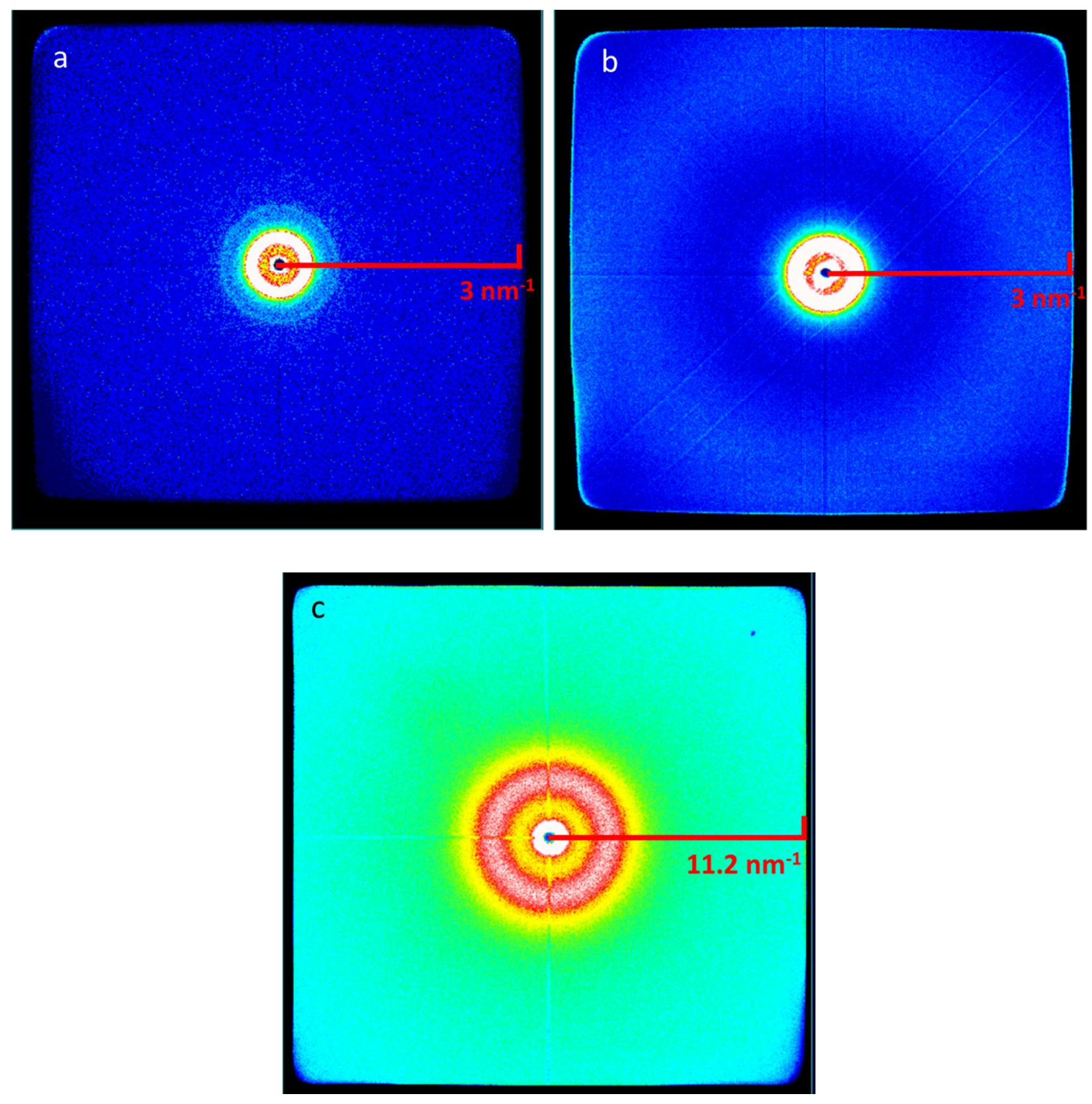

Figure S29. 2D SAXS patterns for $\mathrm{PS}_{89}-\mathrm{PPES}_{41}\left[\mathrm{Co}_{2}(\mathrm{CO})_{6}\right]_{37}$, at a sample-to-detector distance of $1077.7 \mathrm{~mm}\left(0<\mathrm{q}<3.5 \mathrm{~nm}^{-1}\right)$. (a) Sample prior to heating. (b) The same sample, after being heated at $120{ }^{\circ} \mathrm{C}$ for 24 hours. The broad peak near the edge of detector $\left(\mathrm{q} \approx 2 \mathrm{~nm}^{-1}\right)$, indicates the formation of nanoparticles. ${ }^{10}$ (c) The same sample, after heating, at a shorter sample-todetector distance $(277.2 \mathrm{~mm})$, where the nanoparticle scattering ring can be fully observed. 


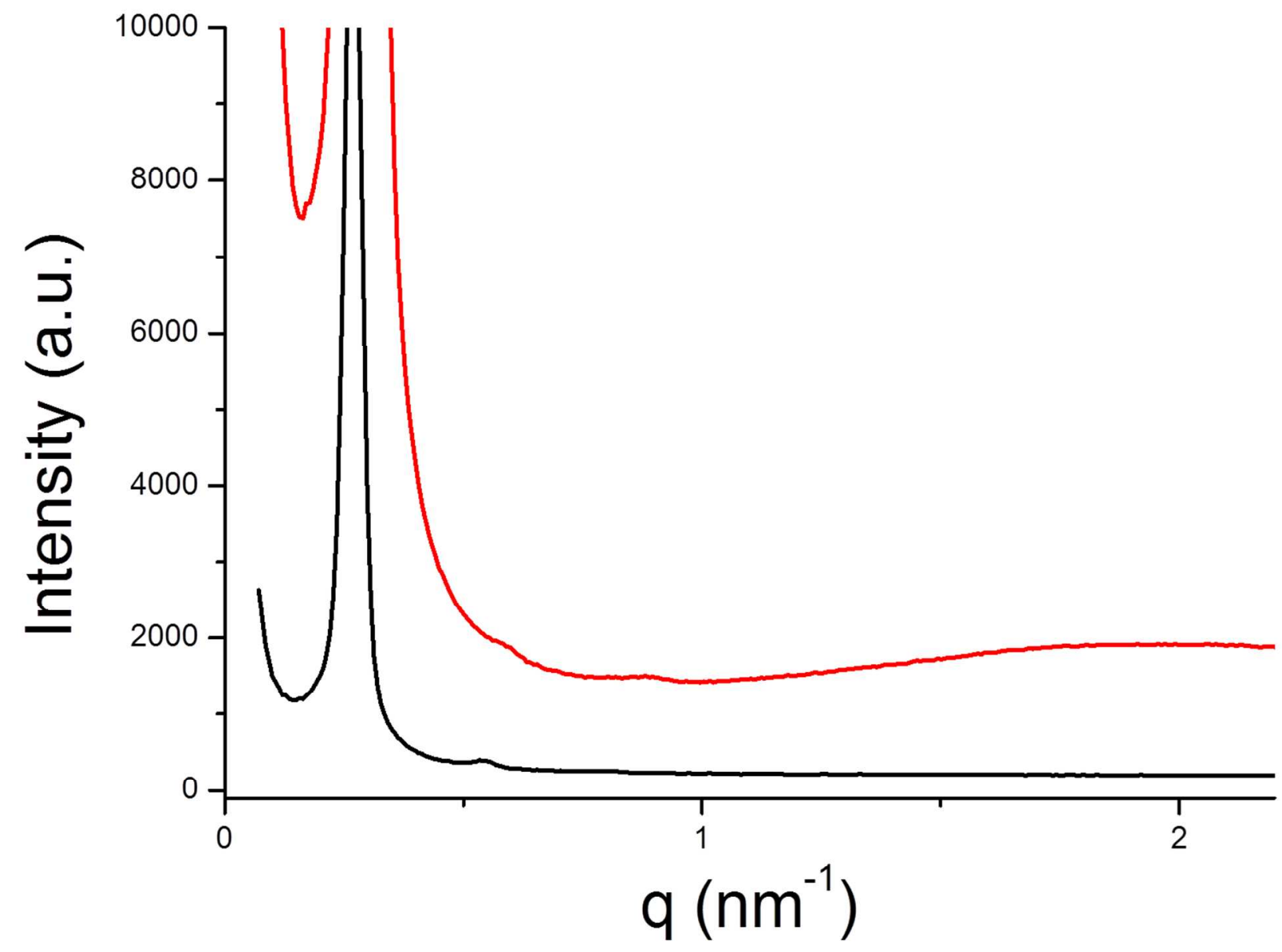

Figure S30. SAXS profiles (linear scale) for sample $\mathrm{PS}_{89}-\mathrm{PPES}_{41}\left[\mathrm{Co}_{2}(\mathrm{CO})_{6}\right]_{36}$ as prepared (bottom black curve) and after heating at $120^{\circ} \mathrm{C}$ for $24 \mathrm{~h}$ (top red curve). The heated sample (top red curve) showed a broad peak spanning from $1.0 \sim 3.0 \mathrm{~nm}^{-1}$. No broad peak was observed in this range prior to heating (bottom black curve). 


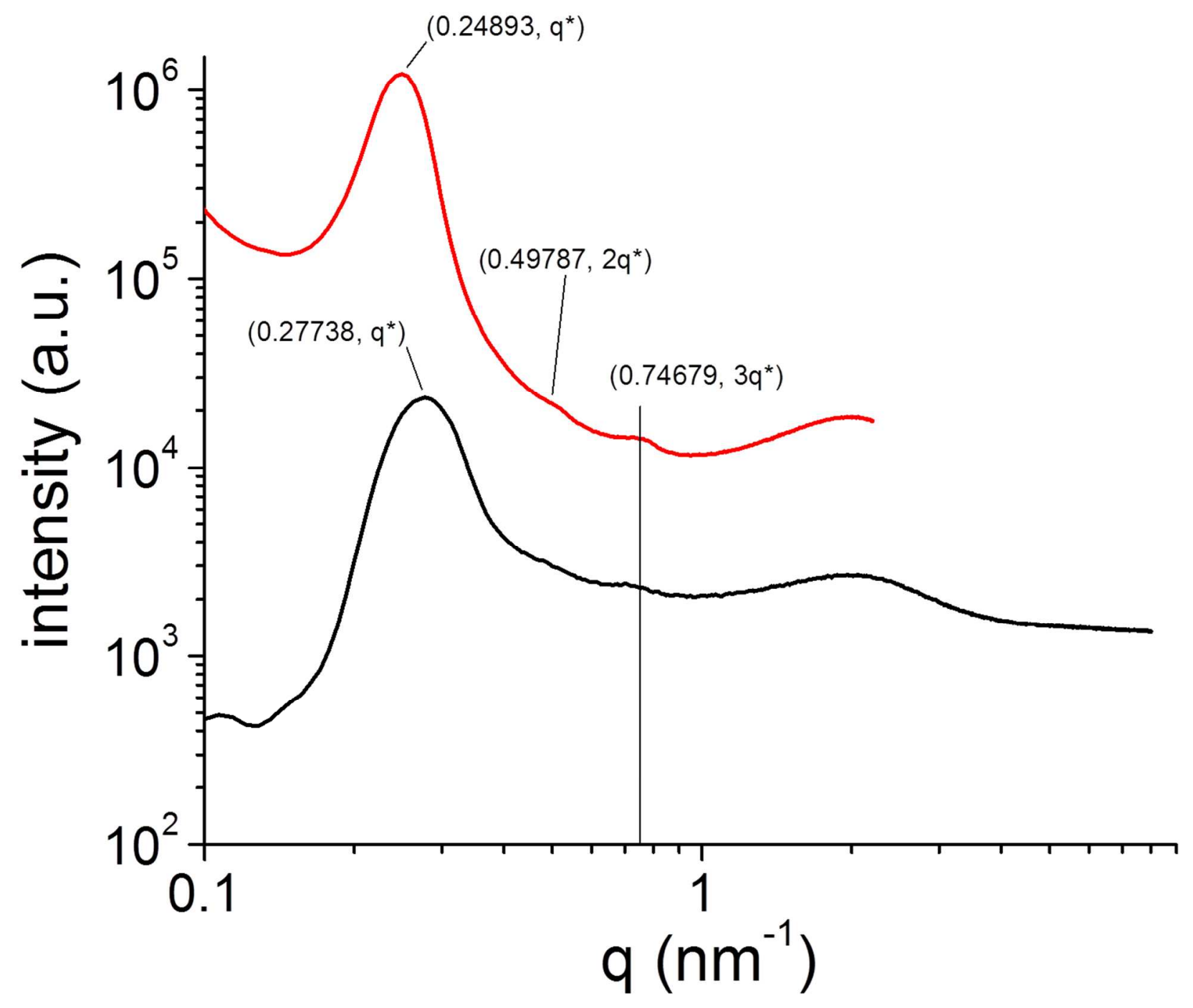

Figure S31. SAXS profiles for $\mathrm{PS}_{116}-\mathrm{PPES}_{48}\left[\mathrm{Co}_{2}(\mathrm{CO})_{6}\right]_{43}$ after heating at $120{ }^{\circ} \mathrm{C}$ for $24 \mathrm{~h}$ at two different sample-to-detector distances $(1077.70 \mathrm{~mm}$, top red trace, and $277.20 \mathrm{~mm}$, bottom black trace). The shorter detector distance $(277.20 \mathrm{~mm})$ gives a more thorough view of the peak at higher scattering vectors (bottom blue trace). The resolution and precision at lower scattering vectors are worse than regular SAXS. 


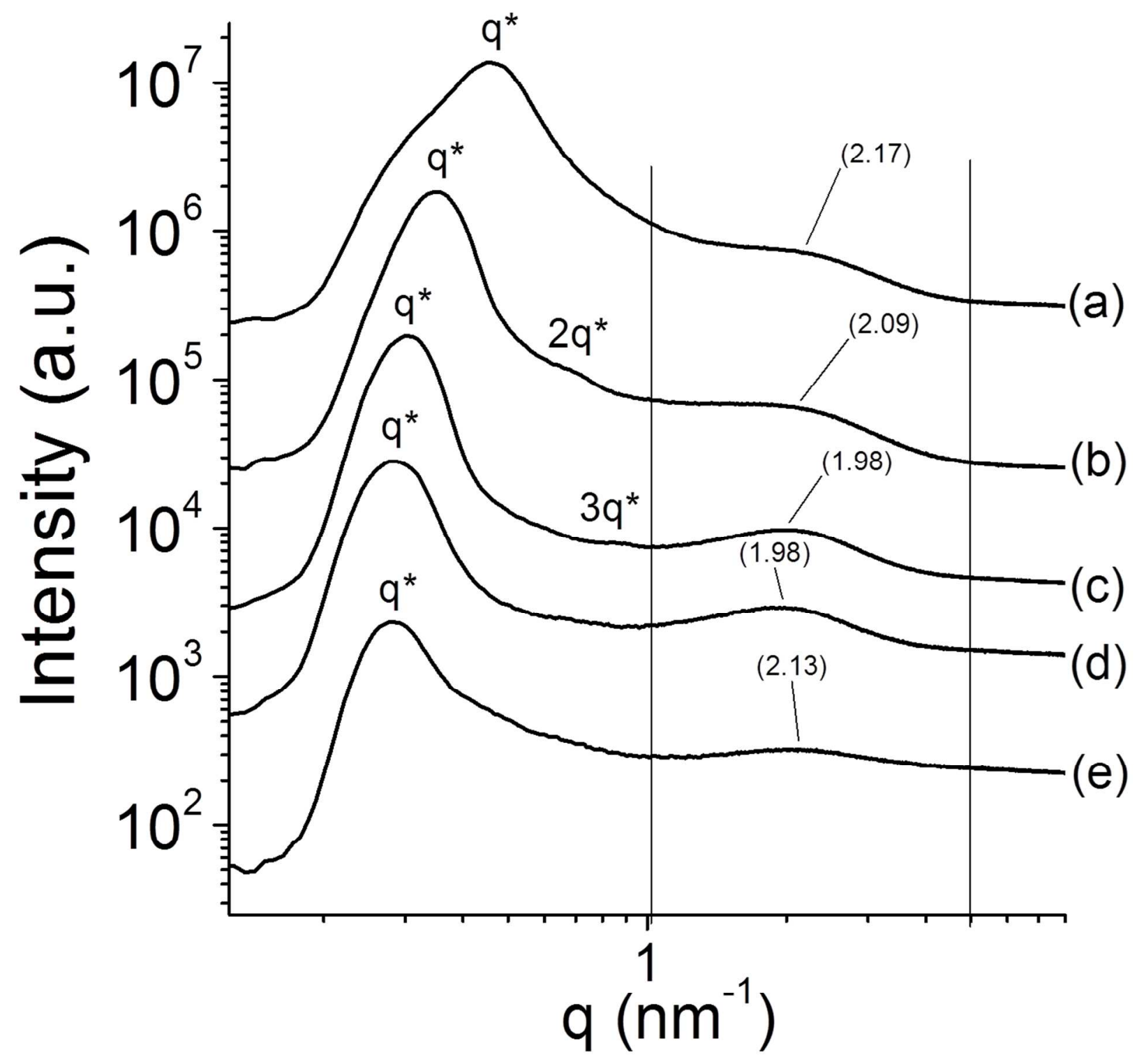

Figure S32. X-ray scattering profiles of samples in $\mathrm{PS}_{89}$-series after heating at $120{ }^{\circ} \mathrm{C}$ for $24 \mathrm{~h}$. (a) $\mathrm{PS}_{89}-\mathrm{PPES}_{9}\left[\mathrm{Co}_{2}(\mathrm{CO})_{6}\right]_{8}$, (b) $\mathrm{PS}_{89}-\mathrm{PPES}_{23}\left[\mathrm{Co}_{2}(\mathrm{CO})_{6}\right]_{21}$, (c) $\mathrm{PS}_{89}-\mathrm{PPES}_{41}\left[\mathrm{Co}_{2}(\mathrm{CO})_{6}\right]_{36}$, (d) $\mathrm{PS}_{89}-\mathrm{PPES}_{67}\left[\mathrm{Co}_{2}(\mathrm{CO})_{6}\right]_{56},(\mathrm{e}) \mathrm{PS}_{89}-\mathrm{PPES}_{89}\left[\mathrm{Co}_{2}(\mathrm{CO})_{6}\right]_{79}$. 
Table S3. Fitting results for modeling of SAXS data for PS-PPES/Co samples after heating.

\begin{tabular}{|c|c|c|c|}
\hline Sample & $\begin{array}{l}\text { Fitted mean } \\
\text { Diameter } \\
(\mathbf{n m})^{\mathrm{a}}\end{array}$ & $\begin{array}{c}\text { Standard deviation } \\
\text { of particle diameter } \\
\text { distribution }(\mathrm{nm})^{\mathrm{a}}\end{array}$ & $\begin{array}{c}\text { Average center-to- } \\
\text { center distance } \\
(\mathbf{n m})^{\mathbf{a}} \\
\end{array}$ \\
\hline $\mathrm{PS}_{89}-\mathrm{PPES}_{9}\left[\mathrm{Co}_{2}(\mathrm{CO})_{6}\right]_{8}$ & 1.4 & 0.8 & 1.9 \\
\hline $\mathrm{PS}_{89}-\mathrm{PPES}_{23}\left[\mathrm{Co}_{2}(\mathrm{CO})_{6}\right]_{21}$ & 1.4 & 0.5 & 2.1 \\
\hline $\mathrm{PS}_{89}-\mathrm{PPES}_{41}\left[\mathrm{Co}_{2}(\mathrm{CO})_{6}\right]_{36}{ }^{\mathrm{b}}$ & 1.2 & 0.7 & 2.4 \\
\hline $\mathrm{PS}_{89}-\mathrm{PPES}_{67}\left[\mathrm{Co}_{2}(\mathrm{CO})_{6}\right]_{56}{ }^{\mathrm{b}}$ & 1.3 & 0.6 & 2.6 \\
\hline $\mathrm{PS}_{89}-\mathrm{PPES}_{89}\left[\mathrm{Co}_{2}(\mathrm{CO})_{6}\right]_{79}{ }^{\mathrm{c}}$ & 0.5 & 0.6 & 2.4 \\
\hline $\mathrm{PS}_{116}-\mathrm{PPES}_{48}\left[\mathrm{Co}_{2}(\mathrm{CO})_{6}\right]_{43}{ }^{\mathrm{b}}$ & 0.9 & 0.7 & 2.5 \\
\hline \multicolumn{4}{|c|}{$\begin{array}{l}\text { The fitting method used is described on p. } 35 \text { of the SI. }{ }^{b} \text { The fitting results for particl } \\
\text { diameters and standard deviation for these samples should be taken with caution, due t } \\
\text { predominant contribution of the structure factor over the weak contribution of form factor to th } \\
\text { scattering. }{ }^{\mathrm{c}} \text { The fitting results for particle size diameter and standard deviation in this sample ar } \\
\text { given for illustrative purposes only. Equally good fits can be obtained for diameters anywher } \\
\text { from } 0.2 \text { to } 1.4 \mathrm{~nm} \text { with a concomitant increase in the width of particle diameter distribution a } \\
\text { mean particle size decreases. }\end{array}$} \\
\hline
\end{tabular}

Table S4. Changes in $d$ spacing for PS-PPES/Co samples after heating at $120^{\circ} \mathrm{C}$ for $24 \mathrm{~h}$.

\begin{tabular}{ccccc}
\hline Polymer/cobalt adducts & $\begin{array}{c}\boldsymbol{q}^{*} \text { before } \\
\text { heating } \\
\left(\mathbf{n m}^{-\mathbf{1}}\right)\end{array}$ & $\begin{array}{c}\boldsymbol{q}^{*} \text { after } \\
\text { heating } \\
\left(\mathbf{n m}^{-\mathbf{1}}\right)\end{array}$ & $\begin{array}{c}\boldsymbol{d} \text { before heating } \\
(\mathbf{n m})\end{array}$ & $\begin{array}{c}\boldsymbol{d} \text { after heating } \\
(\mathbf{n m})\end{array}$ \\
\hline $\mathrm{PS}_{89}-\mathrm{PPES}_{9}\left[\mathrm{Co}_{2}(\mathrm{CO})_{6}\right]_{8}$ & 0.434 & 0.455 & 14.5 & 13.8 \\
$\mathrm{PS}_{89}-\mathrm{PPES}_{23}\left[\mathrm{Co}_{2}(\mathrm{CO})_{6}\right]_{21}$ & 0.313 & 0.349 & 20.1 & 18.0 \\
$\mathrm{PS}_{89}-\mathrm{PPES}_{41}\left[\mathrm{Co}_{2}(\mathrm{CO})_{6}\right]_{36}$ & 0.270 & 0.306 & 23.2 & 20.5 \\
$\mathrm{PS}_{89}-\mathrm{PPES}_{67}\left[\mathrm{Co}_{2}(\mathrm{CO})_{6}\right]_{56}$ & 0.256 & 0.285 & 24.5 & 22.1 \\
$\mathrm{PS}_{89}-\mathrm{PPES}_{89}\left[\mathrm{Co}_{2}(\mathrm{CO})_{6}\right]_{79}$ & 0.235 & 0.277 & 26.8 & 22.7 \\
$\mathrm{PS}_{116}-\mathrm{PPES}_{48}\left[\mathrm{Co}_{2}(\mathrm{CO})_{6}\right]_{43}$ & 0.228 & 0.249 & 27.6 & 25.2 \\
\hline
\end{tabular}

${ }^{a}$ Domain spacing values $(d)$ are calculated from SAXS profiles: $d=2 \pi / q^{*}$. 


\section{Model fitting method used on SAXS data to estimate nanoparticle size.}

The SAXS data were analyzed with IgorPro software, using Irena macro. ${ }^{11}$ For the high $q$ range

$\left(q=0.8\right.$ to $8 \mathrm{~nm}^{-1}$ ), the scattering was fitted to a spherical particle model in the concentrated regime accounting for interference effects in the system (Figure S31 and S32). ${ }^{12}$ Particles were assumed to have a Gaussian size distribution with a cutoff at $0.2 \mathrm{~nm}$ for the smallest size. Fitting parameters for form factor included background value, mean particle diameter, and Gaussian distribution width (standard deviation) (Table S3). Mean distance between particles and particle volume fraction were fitted to the interference model. ${ }^{12}$ The fitting results for mean particle diameters, particle size distribution, and interparticle distances are listed in Table S3. 


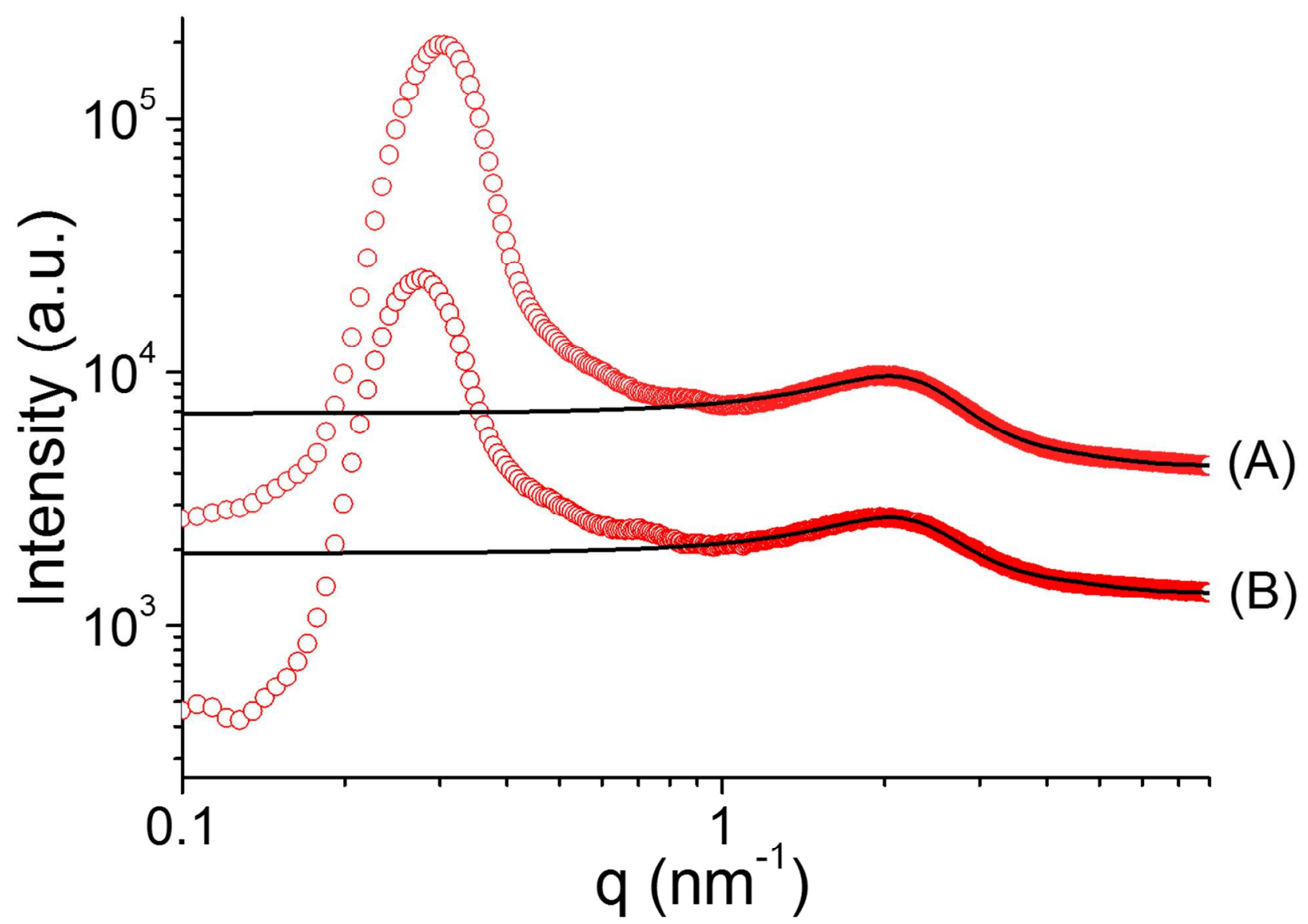

Figure S33. X-ray scattering profiles (red circles) and best fits to nanoparticle size model (black lines) of heated samples $\mathrm{PS}_{89}-\mathrm{PPES}_{41}\left[\mathrm{Co}_{2}(\mathrm{CO})_{6}\right]_{36}(\mathrm{~A})$, and $\mathrm{PS}_{116}-\mathrm{PPES}_{48}\left[\mathrm{Co}_{2}(\mathrm{CO})_{6}\right]_{43}(\mathrm{~B})$. 


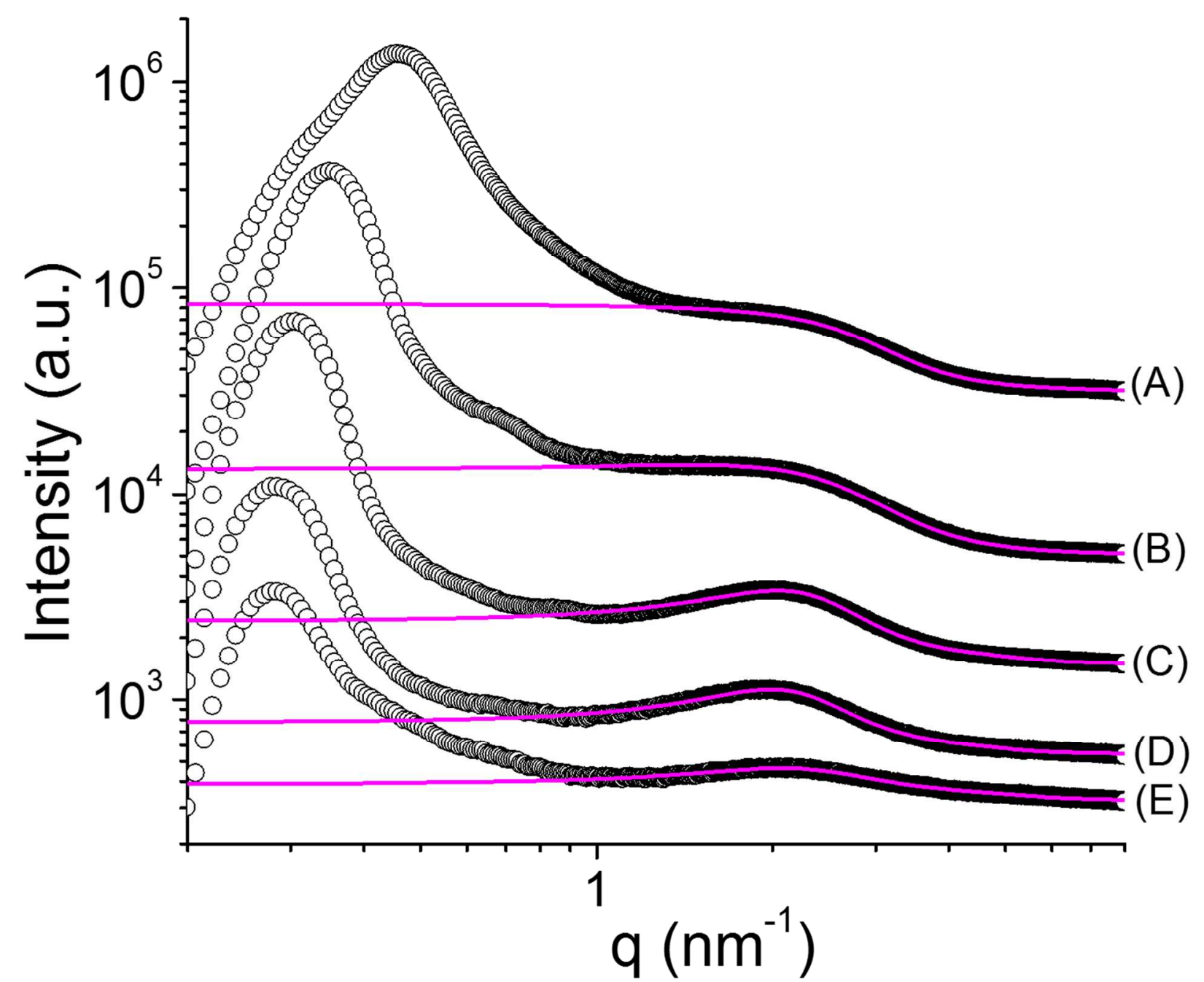

Figure S34. X-ray scattering profiles (black circles) and best fits to nanoparticle model (purple lines) for samples in $\mathrm{PS}_{89}$-series after heating at $120{ }^{\circ} \mathrm{C}$ for $24 \mathrm{~h}$. (A) $\mathrm{PS}_{89}-\mathrm{PPES}_{9}\left[\mathrm{Co}_{2}(\mathrm{CO})_{6}\right]_{8}$, (B) $\mathrm{PS}_{89}-\mathrm{PPES}_{23}\left[\mathrm{Co}_{2}(\mathrm{CO})_{6}\right]_{21},(\mathrm{C}) \mathrm{PS}_{89}-\mathrm{PPES}_{41}\left[\mathrm{Co}_{2}(\mathrm{CO})_{6}\right]_{36},(\mathrm{D}) \mathrm{PS}_{89}-\mathrm{PPES}_{67}\left[\mathrm{Co}_{2}(\mathrm{CO})_{6}\right]_{56},(\mathrm{E})$ $\mathrm{PS}_{89}-\mathrm{PPES}_{89}\left[\mathrm{Co}_{2}(\mathrm{CO})_{6}\right]_{79}$. 


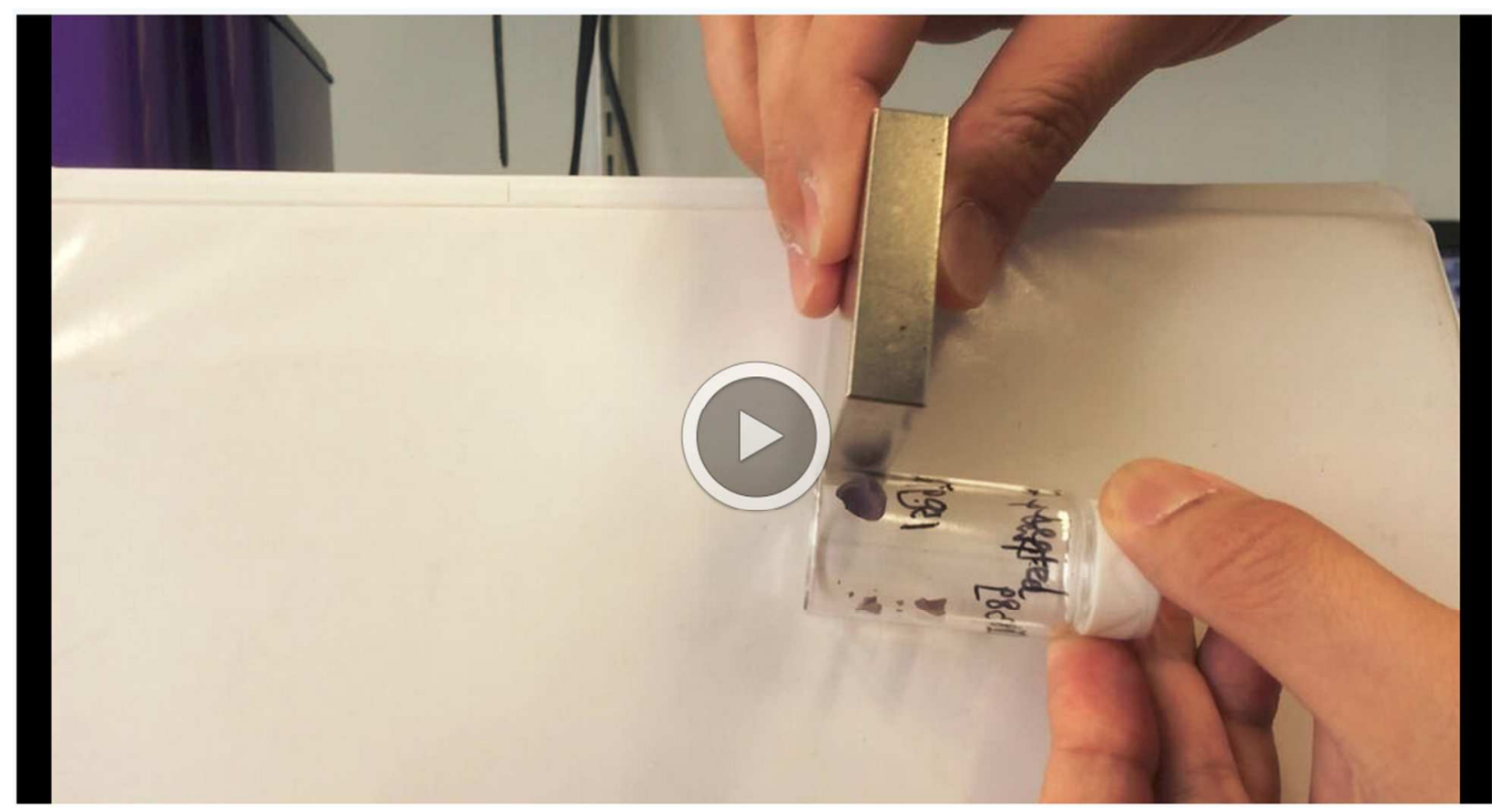

Video S1. Sample $\mathrm{PS}_{40}-\mathrm{PPES}_{39}\left[\mathrm{Co}_{2}(\mathrm{CO})_{6}\right]_{33}$ attracted by a neodymium bar magnet after being heated at $120{ }^{\circ} \mathrm{C}$ for 24 hours.

Ctrl+click the above picture to view the video via dropbox.com; Or go to the following address: https://www.dropbox.com/s/bx2rrn56ltplio7/PS40-PPES39+Co-heated\%20.MOV?dl=0 


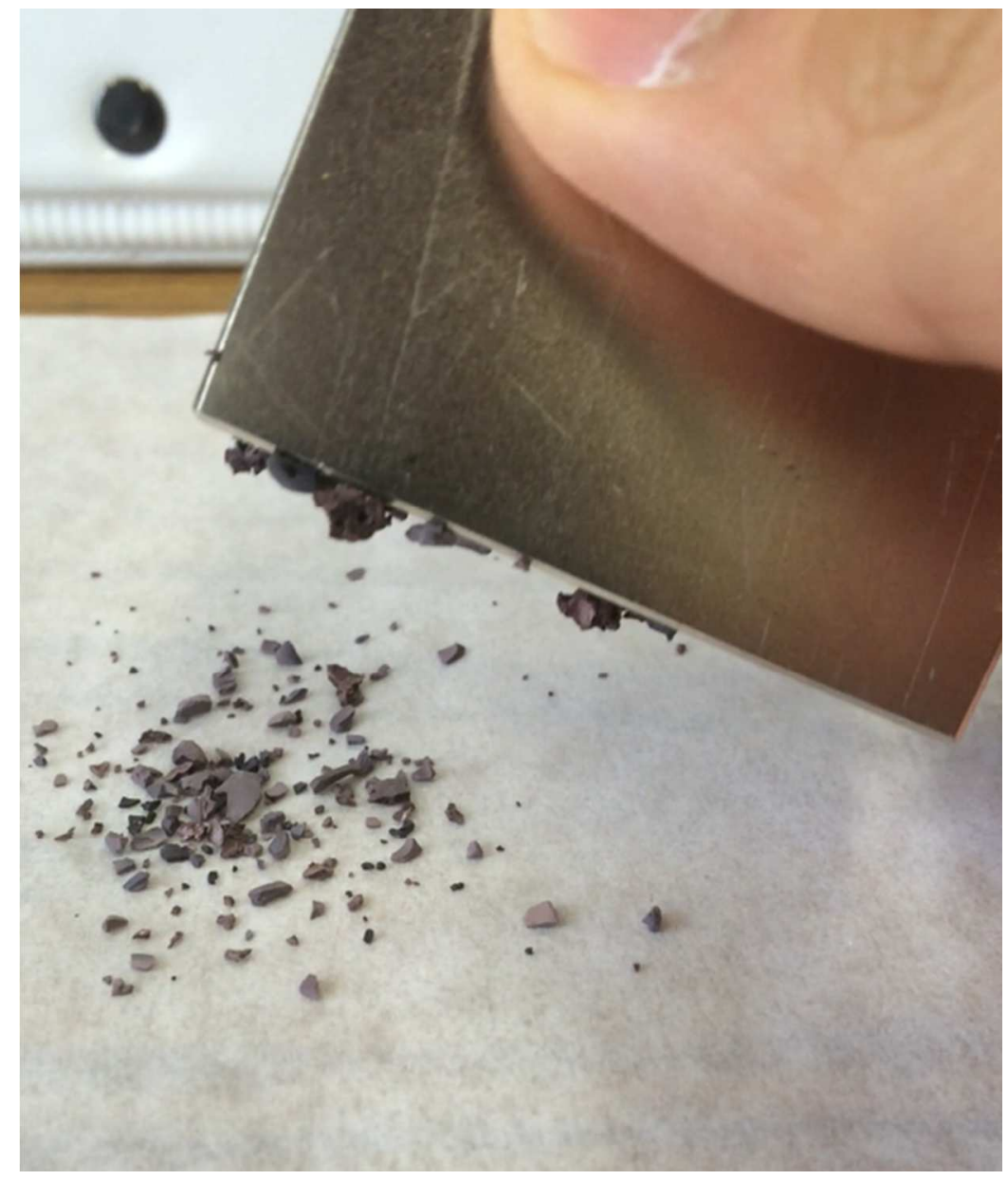

Video S2. Sample $\mathrm{PS}_{89}-\mathrm{PPES}_{41}\left[\mathrm{Co}_{2}(\mathrm{CO})_{6}\right]_{37}$ attracted by a neodymium bar magnet after being heated at $120^{\circ} \mathrm{C}$ for 24 hours.

Ctrl+click the above picture to view the video via dropbox.com; Or go to the following address:

https://www.dropbox.com/s/90wm82f9576zihl/PS89-

PPES41\%20magnetic\%20trimmed.MOV?dl $=0$

\section{References}

1. Hui, J.; Dong, Z.; Shi, Y.; Fu, Z.; Yang, W., Reversible-deactivation radical polymerization of chloroprene and the synthesis of novel polychloroprene-based block copolymers by the RAFT approach. $R S C A d v$. 2014, 4, 55529-55538. doi: 10.1039/c4ra08715a. 2. Hossain, M. D.; Valade, D.; Jia, Z.; Monteiro, M. J., Cyclic polystyrene topologies via RAFT and CuAAC. Polym. Chem. 2012, 3, 2986-2995. doi: 10.1039/c2py20505j.

3. Chong, Y. K.; Krstina, J.; Le, T. P. T.; Moad, G.; Postma, A.; Rizzardo, E.; Thang, S. H., Thiocarbonylthio Compounds [SC(Ph)S-R] in Free Radical Polymerization with Reversible Addition-Fragmentation Chain Transfer (RAFT Polymerization). Role of the Free-Radical Leaving Group (R). Macromolecules 2003, 36, 2256-2272. doi: 10.1021/ma020882h. 
4. Kessler, D.; Theato, P., Synthesis of Functional Inorganic-Organic Hybrid Polymers Based on Poly(silsesquioxanes) and Their Thin Film Properties. Macromolecules 2008, 41, 5237-5244. doi: 10.1021/ma800570x.

5. $\quad$ Miinea, L. A.; Sessions, L. B.; Ericson, K. D.; Glueck, D. S.; Grubbs, R. B., Phenylethynylstyrene-cobalt carbonyl block copolymer composites. Macromolecules 2004, 37, 8967-8972. doi: 10.1021/Ma0490092.

6. Sessions, L. B.; Miinea, L. A.; Ericson, K. D.; Glueck, D. S.; Grubbs, R. B., Alkynefunctional homopolymers and block copolymers through nitroxide-mediated free radical polymerization of 4-(phenylethynyl)styrene. Macromolecules 2005, 38, 2116-2121. doi: 10.1021/Ma048793m.

7. Colombani, O.; Langelier, O.; Martwong, E.; Castignolles, P., Polymerization Kinetics: Monitoring Monomer Conversion Using an Internal Standard and the Key Role of Sample t0. $J$. Chem. Educ. 2011, 88, 116-121. doi: 10.1021/ed100404r.

8. Save, M.; Granvorka, G.; Bernard, J.; Charleux, B.; Boissière, C.; Grosso, D.; Sanchez, C., Atom Transfer Radical Polymerization of Styrene and Methyl Methacrylate from Mesoporous Ordered Silica Particles. Macromol. Rapid Commun. 2006, 27, 393-398. doi: 10.1002/marc.200500798.

9. Van Camp, W.; Gao, H.; Du Prez, F. E.; Matyjaszewski, K., Effect of crosslinker multiplicity on the gel point in ATRP. J. Polym. Sci., Part A: Polym. Chem. 2010, 48, 20162023. doi: 10.1002/pola.23970.

10. Lu, Y.-S.; Kuo, S.-W., Functional groups on POSS nanoparticles influence the selfassembled structures of diblock copolymer composites. RSC Adv. 2014, 4, 34849-34859. doi: $10.1039 / \mathrm{c} 4 \mathrm{ra} 06193 \mathrm{~d}$.

11. Ilavsky, J.; Jemian, P. R., Irena: tool suite for modeling and analysis of small-angle scattering. J. Appl. Crystallogr. 2009, 42, 347-353. doi: 10.1107/s0021889809002222.

12. Beaucage, G.; Ulibarri, T. A.; Black, E. P.; Schaefer, D. W., MULTIPLE SIZE SCALE STRUCTURES IN SILICA-SILOXANE COMPOSITES STUDIED BY SMALL-ANGLE SCATTERING. In Hybrid Organic-Inorganic Composites, Mark, J. E.; Lee, C. Y. C.; Bianconi, P. A., Eds. Amer Chemical Soc: Washington, 1995; Vol. 585, pp 97-111. 